\title{
Meningiomas: knowledge base, treatment outcomes, and uncertainties. A RANO review
}

\author{
Leland Rogers, MD, ${ }^{1}$ Igor Barani, MD, ${ }^{2}$ Marc Chamberlain, MD, ${ }^{3}$ Thomas J. Kaley, MD, ${ }^{4}$ \\ Michael McDermott, MD, ${ }^{5}$ Jeffrey Raizer, MD, ${ }^{6}$ David Schiff, MD, ${ }^{7}$ Damien C. Weber, MD, ${ }^{8}$ \\ Patrick Y. Wen, MD, ${ }^{9}$ and Michael A. Vogelbaum, MD, PhD ${ }^{10}$
}

\begin{abstract}
${ }^{1}$ GammaWest Cancer Services, Radiation Oncology, Salt Lake City, Utah; ${ }^{2}$ Department of Radiation Oncology, University of California, San Francisco, California; ${ }^{3}$ Department of Neurology, University of Washington, Fred Hutchinson Cancer Research Center, Seattle, Washington; 'Division of Neuro-Oncology, Memorial Sloan-Kettering Cancer Center, New York, New York; ${ }^{5}$ Department of Neurosurgery, University of California, San Francisco, California; ${ }^{6}$ Department of Neurology, Northwestern University, Chicago, Illinois; ${ }^{7}$ Neuro-Oncology Center, University of Virginia, Charlottesville, Virginia; ${ }^{8}$ Radiation Oncology, Geneva University Hospital, Geneva, Switzerland; ' $\mathrm{C}$ enter for Neuro-Oncology, Dana-Farber/Brigham and Women's Center, Boston, Massachusetts; and ${ }^{10}$ Brain Tumor and NeuroOncology Center and Department of Neurosurgery, Cleveland Clinic, Cleveland, Ohio
\end{abstract}

\begin{abstract}
Evolving interest in meningioma, the most common primary brain tumor, has refined contemporary management of these tumors. Problematic, however, is the paucity of prospective clinical trials that provide an evidence-based algorithm for managing meningioma. This review summarizes the published literature regarding the treatment of newly diagnosed and recurrent meningioma, with an emphasis on outcomes stratified by WHO tumor grade. Specifically, this review focuses on patient outcomes following treatment (either adjuvant or at recurrence) with surgery or radiation therapy inclusive of radiosurgery and fractionated radiation therapy. Phase II trials for patients with meningioma have recently completed accrual within the Radiation Therapy Oncology Group and the European Organisation for Research and Treatment of Cancer consortia, and Phase III studies are being developed. However, at present, there are no completed prospective, randomized trials assessing the role of either surgery or radiation therapy. Successful completion of future studies will require a multidisciplinary effort, dissemination of the current knowledge base, improved implementation of WHO grading criteria, standardization of response criteria and other outcome end points, and concerted efforts to address weaknesses in present treatment paradigms, particularly for patients with progressive or recurrent low-grade meningioma or with high-grade meningioma. In parallel efforts, Response Assessment in Neuro-Oncology (RANO) subcommittees are developing a paper on systemic therapies for meningioma and a separate article proposing standardized end point and response criteria for meningioma.
\end{abstract}

http://thejns.org/doi/abs/10.3171/2014.7.JNS131644

KEY WORDS meningioma; outcomes; surgery; radiotherapy; oncology

$\mathrm{H}$ ARVEY Cushing first used the term "meningioma" in a 1922 publication describing tumors that originate from the meningeal (dural) coverings of the brain and spinal cord. ${ }^{19}$ Since then, considerable progress has been made, including improved methods of treatment, better characterization of histology with the development of grading systems that provide more accurate prognostic information, use of proliferative markers such as MIB-1, and gains in translational research that have improved the understanding of the molecular genetics of these tumors.
With reference to molecular genetics, meningiomas occur with greater frequency in genetic conditions such as neurofibromatosis Type 2 (NF2) ${ }^{105,106}$ and multiple endocrine neoplasia Type 1 (MEN1). ${ }^{4}$ Nearly all NF2-associated meningiomas, and many sporadic meningiomas, have mutations of the NF2 gene. ${ }^{118}$ Nevertheless, phenotypic NF2 accounts for only a small minority (approximately $1 \%$ ) of meningiomas. MEN1 has also been reported to carry an increased risk for meningioma, although with less likelihood of aberration at the NF2 gene locus. ${ }^{4}$ How-

\footnotetext{
ABBREVIATIONS CGE = cobalt gray equivalent; EBRT = external beam radiation therapy; EORTC = European Organisation for Research and Treatment of Cancer; GTR = gross-total resection; MEN1 = multiple endocrine neoplasia Type 1; NF2 = neurofibromatosis Type 2; PFS = progression-free survival; RANO = Response Assessment in Neuro-Oncology; RTOG = Radiation Therapy Oncology Group; SRS = stereotactic radiosurgery; STR = subtotal resection.

SUBMITTED August 1, 2013. ACCEPTED July 9, 2014.

INCLUDE WHEN CITING Published online October 24, 2014; DOI: 10.3171/2014.7.JNS131644.

DISCLOSURE Dr. Rogers is principle investigator for a meningioma clinical trial (no. RTOG-0539) and received a research grant from the National Cancer Institute in support of the trial. Dr. Raizer has served as a consultant to Roche, EMD Serano, Stemline, and Novartis; has received clinical or research support for this study from Novartis and Roche; and has served on the speakers bureau for Genentech.
} 
ever, there is no clear documentation that NF2- or MEN1associated meningiomas behave more aggressively than their sporadic counterparts.

Incidental, asymptomatic, radiologically presumed meningiomas appear to behave less aggressively $y^{12,139}$ and may be managed with observation, during which treatment may be withheld until symptoms develop, sustained growth occurs, or concerns of encroachment on sensitive structures arise. ${ }^{91}$ The focus of this paper is on larger, symptomatic meningiomas that undergo surgery or other definitive management options stratified by tumor grade, and not a detailed review of incidental, untreated meningiomas. Indeed, the grade of an incidental, observed meningioma is unknown, and its natural history may differ considerably from the larger, symptomatic tumors selected for definitive treatment. Studies have been undertaken to define the natural history of incidental meningiomas, and these results have been described in other papers. ${ }^{12,43,88,89,98,139}$ Further systematic investigations are warranted to delineate which patients are best served by observation, how such observation should be tailored, which subgroups are at higher risk for tumor growth or symptom development, and whether long-term patient outcomes differ between surveillance and early definitive treatment.

Many questions remain regarding the selection and timing of treatment, especially in cases of recurrent meningioma or newly diagnosed high-grade meningioma (WHO Grade II [atypical] or Grade III [malignant] meningioma). For patients undergoing definitive therapy, complete resection has been the standard for meningioma, but there is a significant subset of patients who are not successfully managed by surgery alone, or in whom a complete resection is not possible due to the relationship of the tumor to eloquent anatomy. The potential for recurrence, whether following subtotal resection (STR) or gross-total resection (GTR), is

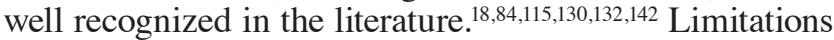
associated with an initial treatment strategy of resection alone are even more apparent for patients with recurrent or high-grade meningioma. ${ }^{2,75}$ The current WHO criteria ${ }^{107}$ have improved the prediction of risk of tumor recurrence, but there remains significant uncertainty. Moreover, the relevance of the original (pre-MRI) Simpson classification based on the extent of resection has been questioned in the MRI era..$^{18,97,138,140}$ In particular, the surgeon's observations at the time of surgery are critical for defining the difference, for example, between a Simpson Grade 1 and Grade 2 excision. Consequently, there needs to be updated agreement regarding how to report the extent of meningioma resection.

Another commonly used treatment for meningioma is radiation therapy, including single-session stereotactic radiosurgery (SRS), hypofractionated stereotactic radiation therapy, and conventionally fractionated external beam radiation therapy (EBRT). A growing number of series have evaluated the use of SRS or EBRT as an adjuvant to surgery after STR for treatment of recurrent low-grade or high-grade meningioma, or as an alternative to surgery. When radiation therapy is used as an alternative to surgery, however, there is no tissue available for grading, or ability to assign a proliferative index or otherwise assess prognosis by histopathological or molecular measures. These studies, which we recognize are largely retrospective or single arm in design, as will be reviewed in this paper, have suggested improved tumor control compared with surgery alone or with observation. At present the most appropriate patients, tumor target volumes, radiation doses, and fractionation schemes are still undefined by prospective trials.

At 5 years, WHO Grade II and III meningiomas carry a 5- to 10-fold greater risk of progression than their initially diagnosed WHO Grade I counterparts. ${ }^{104}$ These tumors can readily become refractory to treatment and entail considerably higher rates of cause-specific mortality. WHO Grade III (anaplastic) meningiomas have short recurrence-free intervals and high mortality rates. Pharmacological approaches, whether adjuvant or primary, are desirable, but have met with limited results. Consequently, considerable opportunity exists for the development of systemic or targeted agents for the treatment of high-grade meningiomas.

As a prelude to discussing outcomes of meningioma by WHO grade, it is important to note that the currently used grading criteria were developed and amended over the course of the last 2 decades. In 1993, the WHO attempted to codify and standardize meningioma grading; previously, many differing grading systems were in use. ${ }^{36,41,80,104}$ The 1993 standards were an important advance, but were subject to considerable subjectivity. The 2000 and 2007 WHO iterations are less vague and more reliably applicable, but much of the pertinent literature is based on prior grading schemes. This renders comparisons among many publications difficult and tenuous.

It is also important to recognize that the reported incidence of all grades of meningiomas has varied substantially over time and by the method of meningioma identification, from 1 to 8.4 per 100,000 people. ${ }^{76}$ Considering both microscopically confirmed and presumed tumors, a recent analysis reported an incidence of 3 to 3.5 per $100,000 .{ }^{47}$ Adjusting for increases in population in the US, approximately 150,000 persons are currently diagnosed with meningioma. ${ }^{15,21}$ Outcomes may vary according to histological and molecular genetic findings, tumor size and location, presenting clinical characteristics, and even the method of identification.

Recognition of the limitations of existing methods to evaluate outcomes of neurooncology patients led to the initiation of an international effort to develop consensus response and outcome evaluation criteria, particularly in the setting of prospective clinical research. This Response Assessment in Neuro-Oncology (RANO) working group consists of a multidisciplinary group of experienced clinical researchers, including neurooncologists, neurosurgeons, radiation oncologists, neuroradiologists, neuropsychologists, and experts in quality of life measures. Open meetings of RANO have included representatives from government, funding and regulatory bodies, and members of the drug and device industry. Recommendations made by the RANO working group are based on expert consensus opinion rather than Level 1 or Level 2 evidence. The primary purpose of this expert opinion process is to recommend a common set of definitions to 
be used in the conduct of clinical research in neurooncology, in this case meningiomas. Previous reviews conducted by the RANO working group have focused on high- and low-grade gliomas, brain metastases, clinical trial design, and surgical applications of novel outcome measures. ${ }^{66,67,117,147,148,151,153}$

Appreciating these important qualifications, this overview examines published treatment outcomes, underscores deficiencies in our meningioma-related knowledge base, provides a foundation for response assessment (for which a future RANO publication is in progress), and suggests opportunities for future research. This paper focuses on surgery and radiation therapy; a companion article will appraise developments and opportunities with systemic therapies.

\section{Methods}

A PubMed literature search encompassing the years 2000 through 2013 for all English-language publications reporting clinical outcomes for patients with surgically or radiotherapeutically treated meningiomas was undertaken. Terms employed in the search were meningioma in multiple combinations that included surgery, radiation therapy, radiosurgery, survival, disease-free survival, progression-free survival, local control, tumor or WHO grade, pathology, atypical, anaplastic, malignant, and derivatives or synonyms of these terms. Bibliographies from the publications identified within PubMed were reviewed to identify further applicable articles. For outcome measures, surgery articles were included if the extent of resection and tumor grade were specified. Radiation therapy publications were included if radiation dose and technical details were described; radiosurgery publications were subject to these same constraints.

Reports were tabulated by year, number of patients, treatment technique, tumor location, mean or median follow-up, histological grade, and outcome measures. For patients receiving surgery, the extent of resection was collected, and for patients receiving radiation therapy or radiosurgery, dose and target volume definitions (when available) were recorded. Applicable outcome measures were recorded, along with their respective time points. The most consistently reported measure was progressionfree survival (PFS) at 5 years, and when possible this was used as a unifying end point.

\section{Results \\ WHO Grade I (Benign) Meningioma}

Meningiomas have long been recognized as the most common nonglial intracranial tumors. ${ }^{11}$ Recent data reveal that they are, in fact, the most frequently reported primary intracranial neoplasms ${ }^{15}$ accounting for $33.8 \%$ of all such tumors. ${ }^{10}$ The majority of meningiomas are benign. With more uniform adoption of the current WHO 2007 standards, approximately $65 \%$ to $80 \%$ are Grade I (Fig. 1). ${ }^{104,155}$

\section{Surgery}

Since the publication of the seminal work of Simp-


FIG. 1. Recurrence-free survival (upper) and overall survival (lower) for 643 patients with meningioma stratified by WHO grade. Among the 643 patients studied, $464(72.2 \%)$ had a Grade I meningioma, $156(24.3 \%)$ a Grade II meningioma, and $23(3.6 \%)$ a Grade III meningioma. ${ }^{104}$ From: Russell \& Rubinstein's Pathology of Tumors of the Nervous System ( $7^{\text {th }}$ ed.). By R.E. McLendon, M.K. Rosenblum, and D.D. Bigner. Copyright (2006) by Hodder Arnold, reproduced by permission of Taylor \& Francis Books UK.

son, maximal resection has been the objective of surgical management for meningiomas. Simpson correlated the extent of resection of tumor, associated dural attachments, and any hyperostotic bone to local recurrence risk and defined 5 grades of resection, which were associated with distinct rates of recurrence. These so-called "Simpson Grades" and their respective recurrence rates are summarized in Table $1 .{ }^{128}$ The completeness of surgical removal has consistently been identified as an important prognostic feature, ${ }^{18,22,112,132}$ and the majority of centers continue to use Simpson's criteria.

Sughrue and colleagues challenged the applicability of the Simpson classification in the present era. In 373 patients with WHO Grade I meningioma followed for a median of 3.7 years, they found no significant differences in 5-year PFS following Simpson Grade 1-4 resections, with 5-year PFS results of 95\%, 85\%, 88\%, and $81 \%$, respectively (p value was nonsignificant). ${ }^{138,140}$ Similar findings were reported previously by Condra et al., ${ }^{18}$ and more recently by Oya et al. ${ }^{97}$ These studies, while identifying no difference in local control after Simpson Grade 1-3 resections, did reveal shorter PFS following Simpson 
TABLE 1. Simpson grades of resection, as derived from a series of 265 patients ${ }^{128}$

\begin{tabular}{clc}
\hline Grade & \multicolumn{1}{c}{ Definition } & Recurrence (\%) \\
\hline 1 & GTR of tumor, dural attachments, \& abnormal bone & 9 \\
\hline 2 & GTR of tumor, coagulation of dural attachments & 19 \\
\hline 3 & $\begin{array}{c}\text { GTR of tumor w/o resection or coagulation of dural attachments or extradural exten- } \\
\text { sions (e.g., invaded or hyperostotic bone) }\end{array}$ & 29 \\
\hline 4 & Partial resection of tumor & 44 \\
\hline 5 & Simple decompression (biopsy) & - \\
\hline
\end{tabular}

Grade 4 surgery. ${ }^{18,97}$ A large series of 391 patients with convexity meningiomas studied by Hasseleid et al., expressly to address modern challenges to the predictive value of the Simpson resection grading system, identified significant outcome differences between Simpson Grade 1 , Grades $2+3$, and Grades $4+5,{ }^{44}$ which served to support the continued applicability of Simpson's criteria.

Gross-total resection (Simpson Grades 1-3) remains the prevalent objective of surgery for meningioma and is achieved in approximately one-half to two-thirds of patients in surgical series inclusive of meningiomas located in a variety of intracranial sites ${ }^{84,112}$ and in more than $95 \%$ of convexity meningiomas. ${ }^{87}$ For benign meningioma, GTR is considered definitive therapy ${ }^{18,84,112,132}$ However, with extended follow-up, recurrences in this setting are not infrequent. ${ }^{1,18,84,130,132,142}$ In 5 separate series, rates of local recurrence after GTR ranged from $7 \%-23 \%$ at 5 years, $20 \%-39 \%$ at 10 years, and $24 \%-60 \%$ at 15 years (Table 2). The higher rates documented in the most recent of these analyses likely reflect the current use of serial evaluation with modern neuroimaging such as MRI. ${ }^{130}$

Subtotal resection (Simpson Grades 4 and 5) carries substantially higher rates of progression in many studies, even in benign meningioma. As shown by the 7 studies summarized in Table 3, local progression rates following STR vary from $37 \%$ to $62 \%$ at 5 years, to $52 \%$ to $100 \%$ at 10 years, and $70 \%$ or greater at 15 years. Condra and colleagues also found that STR affected cause-specific survival. Their patients who underwent STR alone experienced a 15 -year cause-specific survival rate of $51 \%$, significantly inferior to $88 \%$ after GTR and $86 \%$ after STR in addition to radiation therapy $(\mathrm{p}=0.0003) .{ }^{18} \mathrm{In}$ a recent evaluation of clinical and molecular prognostic features of meningioma, Jensen and Lee reported that STR was associated with both poorer PFS and overall survival. ${ }^{54} \mathrm{In}$ spite of these reports, observation remains commonplace following STR. A Mayo Clinic series detailed 581 patients, $116(20 \%)$ of whom underwent STR; only $10(9 \%)$ of these patients received adjuvant radiation therapy. ${ }^{132}$

Patients with WHO Grade I meningioma have lengthy survival expectations (Fig. 1), and thus long-term studies are required to fully understand the risks of progression and death. In studies that have included prolonged evaluation with MRI, higher than expected rates of local progression have been identified ${ }^{130}$ (Table 3). Moreover, recurrent meningioma exhibits a several-fold increased risk of progression and a shorter interval to progression than newly diagnosed tumors. ${ }^{18,83,84,142}$ Miralbell et al. reported an 8-year PFS rate of $11 \%$ in recurrent tumor with surgery alone, compared with a rate of $78 \%$ following a combination of surgery and adjuvant EBRT. ${ }^{83}$ Taylor et al. found a 5 -year PFS rate of $30 \%$ with surgery alone for recurrent meningioma, compared with $88 \%$ for surgery and EBRT; they also reported 5-year overall survival rates of $45 \%$ and $90 \%$, respectively. ${ }^{142}$ These data support the need for prospective clinical investigation of methods to prevent recurrence and provide impetus for research into clinical, imaging, histopathological, and molecular predictors of response to treatment and to tumor progression.

\section{Radiation Therapy}

Multiple retrospective studies have demonstrated that various forms of radiation therapy, including SRS and EBRT, can provide improved and durable local control in selected patients with meningioma. Radiation therapy has most commonly been used as an adjunct to surgery following STR, as treatment for recurrence, or for tumors of high-grade histology. Additionally, as shown in Tables 4 and 5, many studies document excellent local control with SRS or EBRT as a primary modality. In these stud-

TABLE 2. Five single-institution series with prolonged follow-up, documenting rates of recurrence following GTR alone of benign meningiomas

\begin{tabular}{llcccc}
\hline & & & \multicolumn{3}{c}{ Local Recurrence Rate (\%) } \\
\cline { 4 - 6 } Authors \& Year & \multicolumn{1}{c}{ Institution } & No. of Patients & $5-Y r$ & 10-Yr & $15-Y r$ \\
\hline Mirimanoff et al., 1985 & MGH & 145 & 7 & 20 & 32 \\
\hline Taylor et al., 1988 & University of Florida & 90 & $13^{*}$ & $25^{*}$ & $33^{*}$ \\
\hline Condra et al., 1997 & University of Florida & 175 & 7 & 20 & 24 \\
\hline Stafford et al., 1998 & Mayo Clinic & 465 & 12 & 25 & - \\
\hline Soyuer et al., 2004 & MD Anderson & 48 & 23 & 39 & $60^{*}$ \\
\hline Total & & 923 & $7-23$ & $20-39$ & $24-60$ \\
\hline
\end{tabular}

MGH = Massachusetts General Hospital.

* Data extracted from graph. 
TABLE 3. Seven single-institution series with prolonged follow-up, assessing rates of recurrence following STR alone of benign meningiomas

\begin{tabular}{llrrrr}
\hline & & & \multicolumn{3}{c}{ Local Progression Rate (\%) } \\
\cline { 4 - 6 } Authors \& Year & Institution & No. of Patients & $5-Y r$ & 10-Yr & $15-Y r$ \\
\hline Wara et al., 1975 & UCSF & 58 & 47 & 62 & - \\
\hline Barbaro et al., 1987 & UCSF & 30 & $40^{*}$ & $100^{*}$ & - \\
\hline Mirimanoff et al., 1985 & MGH & 80 & 37 & 55 & 91 \\
\hline Condra et al., 1997 & University of Florida & 55 & 47 & 60 & 70 \\
\hline Miralbell et al., 1992 & MGH & 79 & 40 & $52 \dagger$ & - \\
\hline Stafford et al., 1998 & Mayo Clinic & 116 & 39 & 61 & - \\
\hline Soyuer et al., 2004 & MD Anderson & 32 & 62 & $82^{*}$ & $87^{*}$ \\
\hline Total & & 450 & $37-62$ & $52-100$ & $70-91$ \\
\hline UCSF = University of California, San Francisco. & & & &
\end{tabular}

ies, radiation therapy was used predominantly for tumors in locations that are difficult to surgically access, such as the optic nerve sheath or cavernous sinus, and for patients regarded as inoperable for medical reasons or for those who chose primary radiation therapy over surgery. ${ }^{31,63,64,68,73,77,101,113,123}$ These studies show that radiation therapy achieved long-term local control in $68 \%$ to $100 \%$ of WHO Grade I or presumed Grade I meningiomas at 5 to 10 years, including patients treated postoperatively, primarily, or following recurrence. Results varied somewhat by treatment era, tumor size and location, and clinical setting.

\section{Stereotactic Radiosurgery}

Stereotactic radiosurgery was developed more recently than fractionated EBRT, and over the past 2 to 3 decades has been used with increasing frequency. Stereotactic radiosurgery has been used after STR or for recurrence, ${ }^{58,62,133}$ and as a definitive primary treatment. ${ }^{31,113-115}$ Table 4 includes 35 studies of SRS and demonstrates that local control was achieved in the majority of patients at 5 to 10 years.

Stereotactic radiosurgery is considered most effective for patients with small meningiomas, typically those that are less than $3 \mathrm{~cm}$ in diameter or $10 \mathrm{~cm}^{3}$ in volume, those with distinct margins, and those at sufficient distance from functionally important brain, nerves, and other critical structures to permit safe delivery of an adequate target dose. For WHO Grade I meningioma, excellent local control has consistently been achieved with 12 to 16 Gy (Table 4). Ganz and colleagues noted that a minimum peripheral tumor dose of 10 Gy or less was associated with higher failure risk, compared with a dose of at least $12 \mathrm{~Gy} .^{32}$ Stafford et al. reported no reduction in local control at 5 years with tumor margin doses of less than 16 Gy as compared with doses greater than or equal to 16 Gy. ${ }^{133}$ Similarly, Kondziolka et al. reported no improvement with marginal doses greater than $15 \mathrm{~Gy}$ versus less than 15 Gy. ${ }^{60}$

With respect to tumor size, DiBiase and colleagues reported a 91.9\% 5-year disease-free survival for patients with meningiomas less than $10 \mathrm{~cm}^{3}$ (equivalent diameter $2.7 \mathrm{~cm}$ ), as opposed to $68 \%$ for larger tumors. ${ }^{24}$ Kondzi- olka et al. reported excellent outcomes with SRS for meningiomas up to a diameter of $3.0 \mathrm{~cm}$ or a volume of 7.5 $\mathrm{cm}^{3} .^{60}$ Likewise, other authors have found excellent local control and fewer radiation-related complications with smaller meningiomas, with complications in $4.8 \%$ of patients with tumors in the smallest quartile $\left(<3.2 \mathrm{~cm}^{3}\right)$ but in $22.6 \%$ in the largest quartile $\left(>9.6 \mathrm{~cm}^{3}\right) .{ }^{113,114}$

Pollock et al. reported on 188 patients with benign or presumed benign meningiomas treated using either surgery or SRS alone. With a median follow-up of 64 months, 7-year PFS with SRS and Simpson Grade 1 surgery were equivalent (95\% and 96\%, respectively). However, SRS resulted in superior tumor control when compared with less extensive surgery. The authors concluded that SRS should be a primary option when Simpson Grade 1 resection is unlikely. ${ }^{15} \mathrm{In}$ an updated analysis of primary SRS, Pollock and colleagues found 10-year local control was $99.4 \%$, using a mean tumor margin dose of $15.8 \mathrm{~Gy}$. No patient developed marginal recurrence. These results suggest that Grade I meningioma can often be accurately defined and well controlled with SRS as primary therapy. However, emphasizing the requirement for prolonged evaluation, 2 patients developed local progression more than 12 years after SRS..$^{113,114}$

SRS for meningioma has traditionally involved a single session, but reports of multisession SRS are emerging. ${ }^{17,33,69,73,86,144}$ These studies appear to demonstrate comparable local control to single-fraction treatment, with perhaps fewer side effects and a lower incidence of symptomatic edema, particularly for nonbasal/parasagittal or large meningiomas. In 1 of these reports, Unger et al. reported on 173 patients and found that symptomatic edema was significantly less common following multifraction SRS (typically 25 Gy in 5 fractions) than single-session SRS (median $15 \mathrm{~Gy}$ ); the respective 2-year actuarial risks were $3.2 \%$ and $12.5 \%$. Single-session SRS and tumor volume greater than $4.9 \mathrm{~cm}^{3}$ were significant predictors of symptomatic edema. ${ }^{144}$

Girvigian et al. published a study involving 30 patients with convexity or parasagittal meningiomas, 14 treated with single-fraction and 16 with multifraction SRS. Multifraction treatment was typically 25 Gy in 5 fractions, and 
.

言

๕

产思 $\stackrel{\mathbb{Q}}{\propto}$

$\widehat{\varrho}$

정

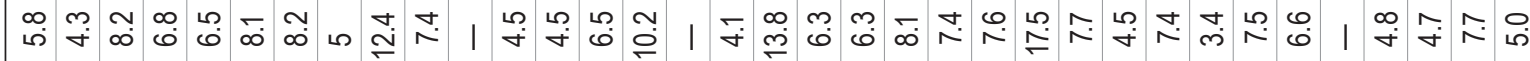

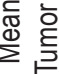

吢

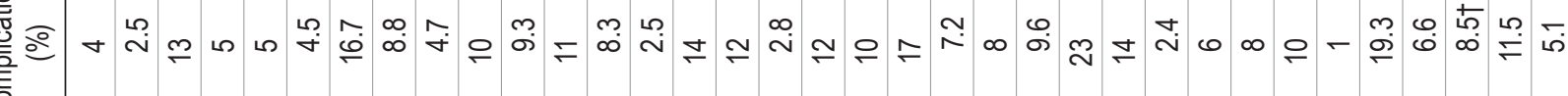

U

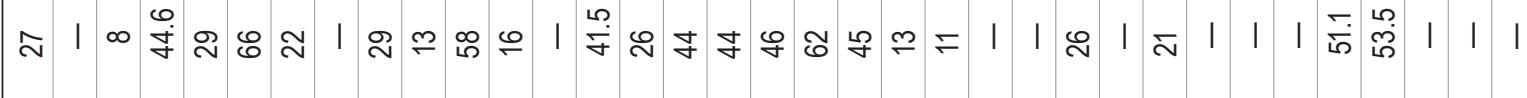
高

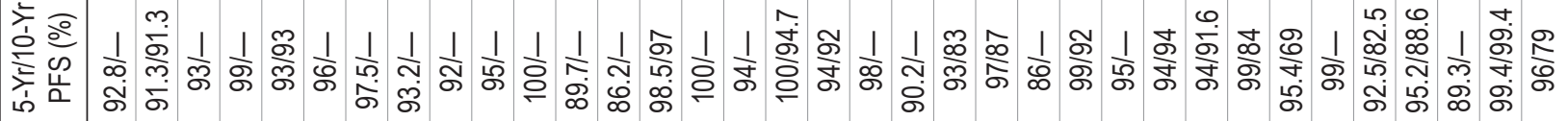

든

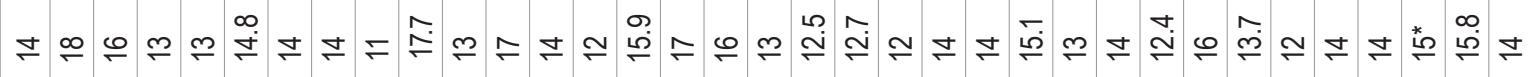

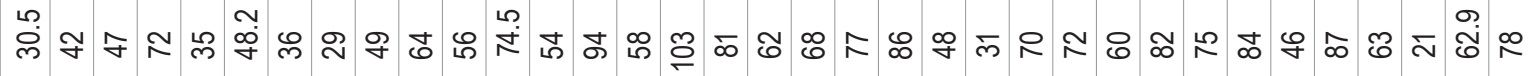

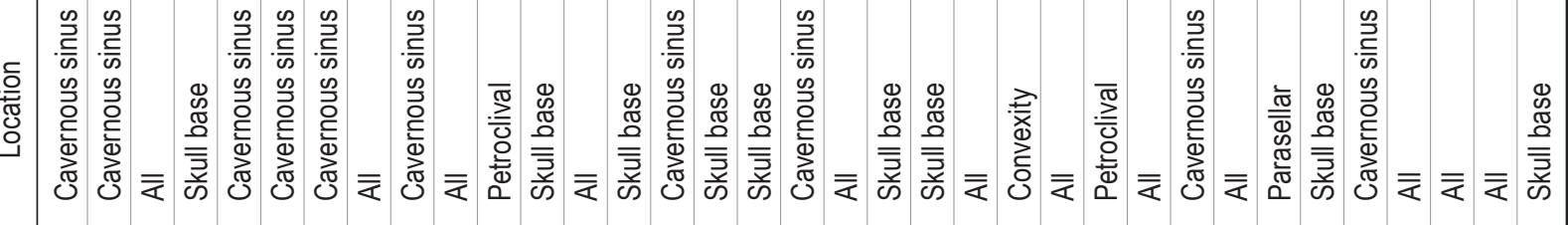

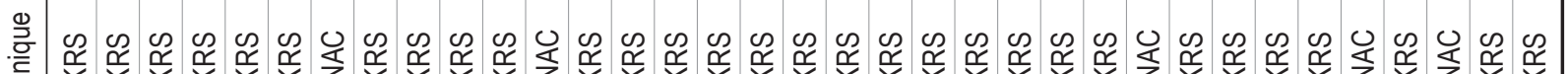

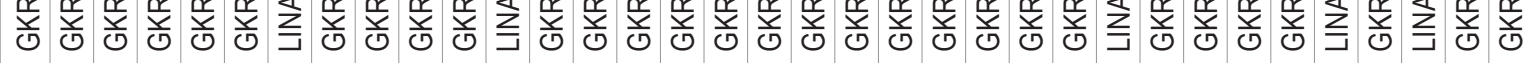
(1) 0 0

뉸 畩

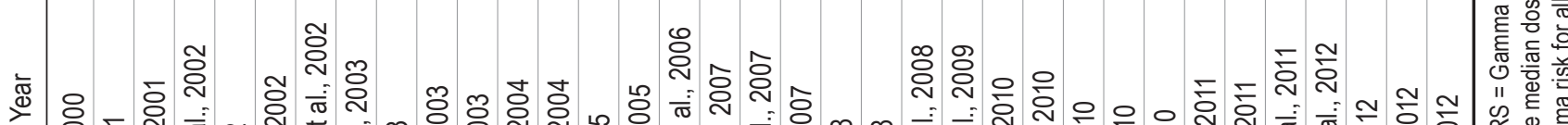


TABLE 5. Thirty-five studies of fractionated EBRT for patients with largely WHO Grade I or presumed Grade I meningiomas

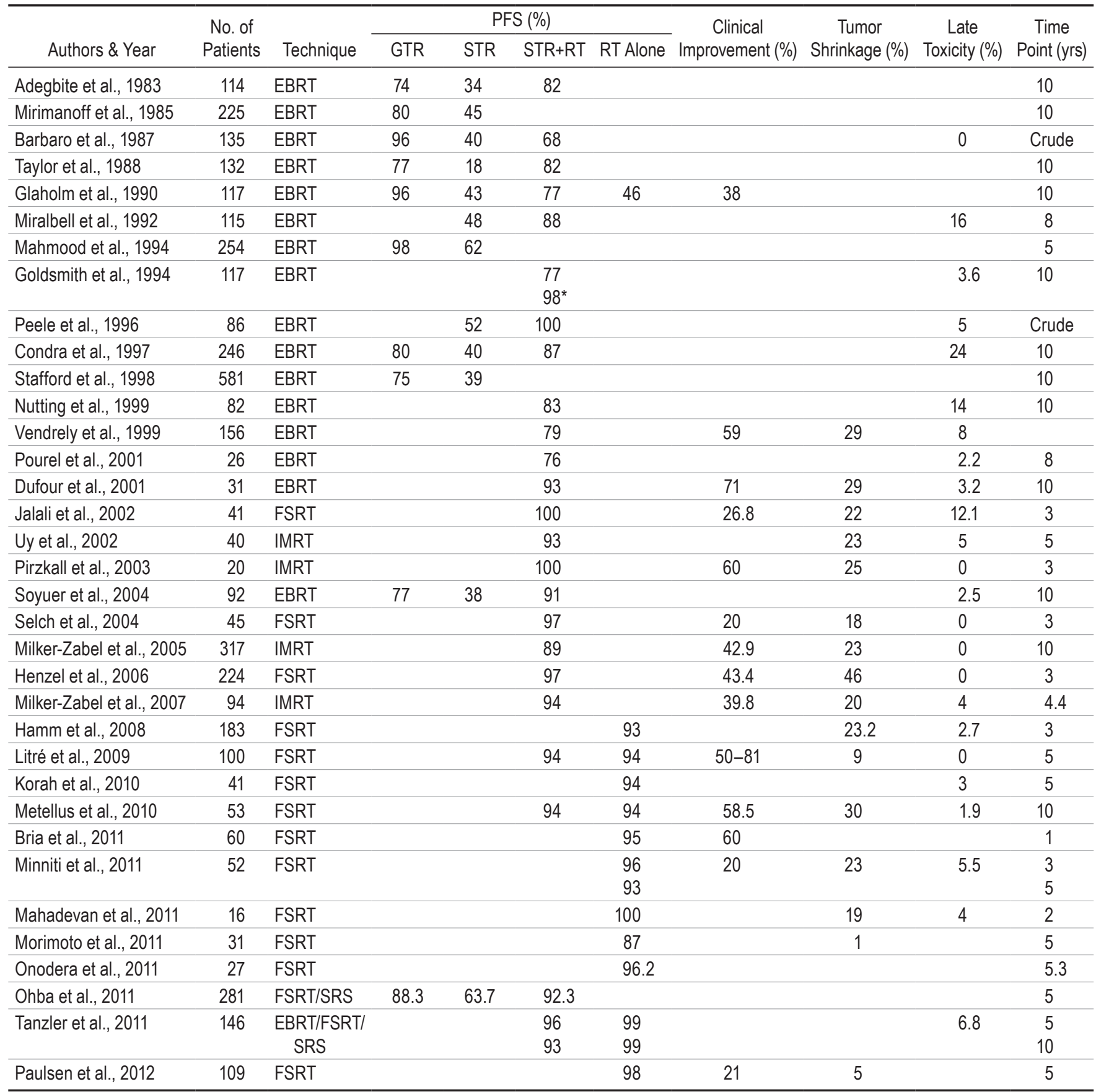

FSRT = fractionated stereotactic radiation therapy; IMRT = intensity-modulated radiation therapy; RT = radiation therapy.

* Ten-year PFS rate of $98 \%$ with treatment after 1980 when CT and MRI began to be used for treatment planning, versus $77 \%$ before 1980 .

was used for larger tumors. Symptomatic edema occurred in $43 \%$ following single-fraction SRS, as opposed to $6.3 \%$ (1 patient) after multifraction SRS, and this patient had pretreatment edema. Single doses of more than $14 \mathrm{~Gy}$ and larger tumor volume were predictors of edema. ${ }^{33}$

Columbo et al. reported on 49 patients who received single-fraction SRS (11-13 Gy) and 150 patients with tumors close to critical structures and/or greater than $8 \mathrm{~cm}^{3}$ in volume who were treated with multifraction SRS (1425 Gy in 2-5 fractions). For the entire cohort, 5-year PFS was $93 \%$. Columbo et al. observed very few treatmentrelated complications, even in patients with large tumors, and maintained that with the use of multifraction SRS they were able to treat 63 patients who could not have been treated by single-fraction techniques. ${ }^{17}$

\section{Fractionated EBRT}

Historically, meningiomas have been considered resistant to irradiation, probably due to infrequent documentation of tumor regression following the use of EBRT. EBRT 
was also believed to produce considerable side effects, to potentiate malignant degeneration, and indeed to cause meningiomas. ${ }^{58,84,121,137}$ These concerns likely remain an issue today, and as a consequence many patients with inoperable or subtotally resected meningioma are managed by observation. ${ }^{3,132}$ A recent publication by Sughrue et al. reported the outcomes of 373 patients with newly diagnosed WHO Grade I meningiomas, the preponderance located at the skull base, treated using surgery alone. Simpson resection grades were Grade 1 in 88 patients (23.6\%), Grade 2 in 114 (30.6\%), Grade 3 in 57 (15.3\%), and Grade 4 in $114(30.6 \%),{ }^{138,140}$ indicating that many patients with a subtotally resected meningioma continue to be managed without adjuvant therapy.

Regarding the risk of radiation-associated tumor dedifferentiation (i.e., transformation to a higher tumor grade), reliable estimates are difficult to ascertain. Dedifferentiation has not been definitively linked to radiation therapy. Furthermore, advancing tumor grade is the natural history of a subgroup of recurrent or progressive meningioma. ${ }^{52,93}$ To establish radiation-induced malignant transformation, detailed histology prior to irradiation would be indispensable. Moreover, radiation is often used only after imagingconfirmed regrowth, without additional histological analysis. Thus, whether dedifferentiation results from irradiation or as a result of natural cellular evolution cannot be readily determined..$^{93}$ This raises the question of whether some advanced imaging surrogate of histology could be developed and used to help guide therapy and predict outcomes.

The risk of developing a meningioma after cranial irradiation has been reviewed by Strojan et al., who reported an actuarial risk of $0.53 \%$ at 5 years and $8.18 \%$ at 25 years. ${ }^{137}$ This risk appears to be considerably smaller with modern, highly conformal therapy. Minniti et al. reported on 426 patients with pituitary adenoma treated using surgery and small-field EBRT and followed for 5749 personyears. The risk of a second brain tumor at 20 years was $2.4 \%$. Of the 11 second tumors, 5 were meningiomas. ${ }^{82}$ With even smaller field treatment using SRS, and with more than 9000 patients, Niranjan and colleagues estimated a second tumor risk of less than 1 per $1000 .{ }^{93}$ This risk is smaller than that reported for the published series using larger field nonconformal EBRT, but with modern, highly conformal approaches to fractionated EBRT, improved outcomes relative to older series may be expected.

Outcomes data from 35 studies of EBRT for meningioma are described in Table 5. These studies, while retrospective in nature, provide evidence that EBRT can improve PFS when used as an adjunct to STR, as salvage treatment of meningioma at recurrence, or as primary therapy. Excellent long-term outcomes from primary EBRT are reported for optic nerve sheath meningiomas. For these tumors, surgery carries a high risk of visual complications and a high rate of local recurrence, whereas EBRT alone results in more favorable outcomes than observation, surgery, or surgery in addition to EBRT. ${ }^{90,101,143}$ Moreover, patients with optic nerve sheath meningiomas commonly experience improved visual acuity following use of EBRT.90,101,143,146

Primary EBRT for intracranial meningiomas not involving the optic nerve sheath has also resulted in excel- lent local control, clinical improvement, and low rates of toxicity (Table 5). Tanzler et al. studied 88 patients treated with definitive EBRT (mean total dose 52.7Gy). The majority of patients were diagnosed on the basis of imaging findings alone. Median follow-up for living patients was 8 years, and 10 -year local control was $99 \% .141$

Technical improvements in the delivery of EBRT have favorably affected the outcome and side effects of this treatment modality. Treatment is now delivered with more precision and conformality, and improvements in local control have been documented. Goldsmith et al. and Milosevic et al. each substantiated improvements in local control with modern imaging. ${ }^{35,36,80}$ Goldsmith found that, with immobilization techniques and with CT- or MRIbased planning, 10-year PFS improved from $77 \%$ to $98 \%$ $(\mathrm{p}=0.002)^{35,36}$

Recommended EBRT doses for benign meningiomas are generally $50-55$ Gy with fraction sizes of $1.8-2.0 \mathrm{~Gy},{ }^{18,35}$ but a dose-response relationship has not been unequivocally established. Goldsmith et al. reported that doses greater than 52 Gy resulted in improved 10-year local control, but this effect was not substantiated on multivariate analysis. ${ }^{36}$ Winkler and colleagues found no clear dose-response from 36 to 79.5 Gy (1.5-2.0 Gy per day). ${ }^{156}$ A common dosing schedule for WHO Grade I meningioma is 54 Gy in 27 to 30 fractions, although for meningioma of the optic nerve sheath or near the anterior visual pathway, lower total doses in the range of $50 \mathrm{~Gy}$ and even modestly lower doses per fraction have achieved good results. ${ }^{90,126}$ Figure 2 displays preoperative and postoperative MR images and the dosimetry plan CT for EBRT on a patient with a subtotally resected WHO Grade I meningioma. The prescription dose was 5400 cGy in 30 fractions.

Radiation treatment-related edema has rarely been reported with EBRT. In 35 studies involving 4389 patients (Table 5), less than $0.5 \%$ of patients were reported to have developed treatment-related edema. It should be noted, however, that many studies did not specifically assess edema, and some patients with treatment-related edema, especially if asymptomatic, may have escaped detection. However, Selch and colleagues specifically examined the rate of treatment-related edema in 45 patients and found no cases of post-EBRT edema with a median follow-up of 3-years. ${ }^{124}$ Tanzler et al. studied 146 patients treated with EBRT and 2 (1.4\%) developed edema. ${ }^{141}$ It appears that edema is a less likely consequence of EBRT than of single-fraction SRS. Delayed neurotoxicity is also an important consideration, but little is known with specific reference to patients with meningioma, so this represents an avenue for further research.

\section{WHO Grade II (Atypical) Meningioma}

Although for decades Grade II meningiomas were identified in only about $5 \%$ of cases, with the adoption of the 2000 and 2007 WHO criteria, they now constitute $20 \%-35 \%$ of newly diagnosed meningiomas. ${ }^{15,102,104,155}$ Given this magnitude of change in their identification, investigation is needed to redefine the natural history expectations for these tumors and to better define the results of treatment. Furthermore, assessment is needed to determine how uniformly the new WHO diagnostic criteria are 

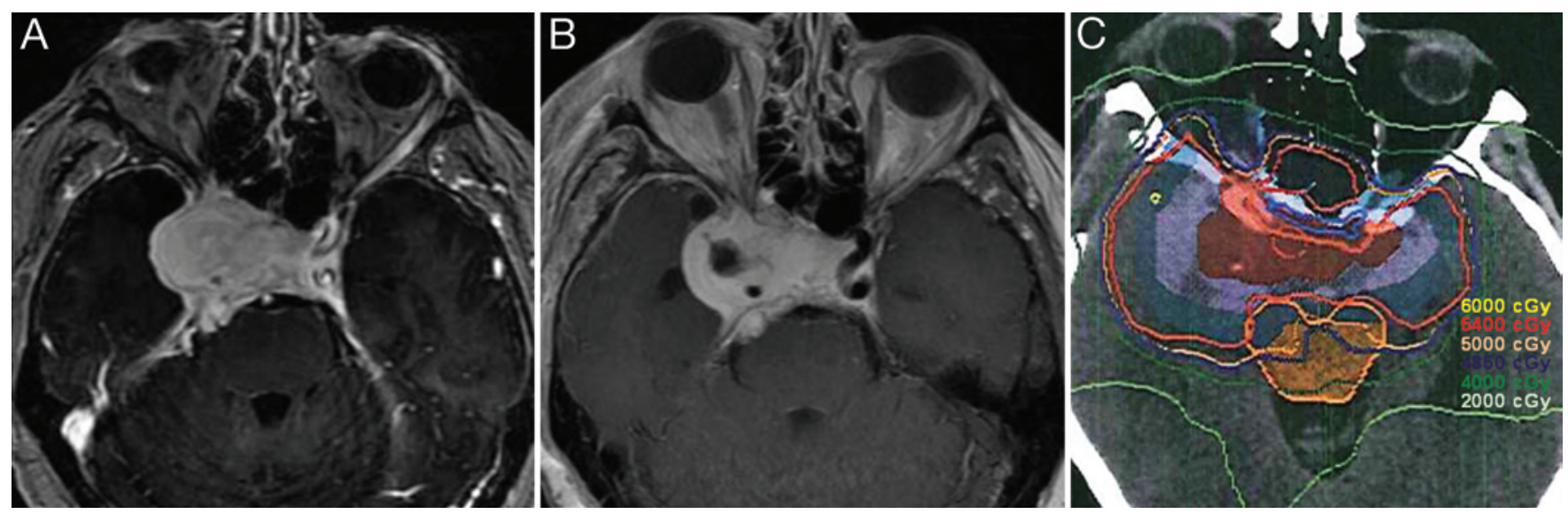

FIG. 2. Preoperative (A) and postoperative (B) axial MR images as well as the dosimetry plan CT scan (C) for EBRT in a patient with a subtotally resected WHO Grade I meningioma. The prescription dose was $5400 \mathrm{cGy}$ in 30 fractions (180 cGy per fraction). Courtesy of Heyoung McBride, MD, and Terry Thomas, MS, Barrow Neurological Institute, Phoenix, Arizona. Figure is available in color online only.

being implemented, and to define the rates of interobserver and interinstitutional concordance in diagnosis. These investigations are crucial because, as shown in Fig. 1, atypical meningioma carries a 7 - to 8 -fold increased risk of recurrence at 5 years and an increased rate of mortality compared with WHO Grade I meningioma. ${ }^{104}$

\section{Surgery}

When evaluating the impact of treatment on atypical meningioma, it is critical to keep in mind that the literature consists of retrospective reports, and that most include patients diagnosed using pre-WHO pathological criteria, which underreported the incidence of atypical meningioma. Both the recently completed Radiation Therapy Oncology Group (RTOG) and European Organisation for Research and Treatment of Cancer (EORTC) prospective trials included central review of pathology, and analysis of their pathological material is eagerly awaited. There is general agreement, but not consensus, that STR alone is insufficient treatment for WHO Grade II meningioma. Surveys among neurosurgeons in Germany and the United Kingdom indicated that $26 \%$ and $41 \%$, respectively, do not recommended adjuvant therapy after STR of an atypical meningioma. ${ }^{74,127}$ Another single-institution series reported a 10 -year local control rate of $17 \%$ following STR of atypical meningioma but could not document a significant benefit associated with the use of postoperative radiation therapy. ${ }^{37}$ In general, neurosurgeons have used the strategy of serial re-resection to manage Grade II meningioma recurrence.

There is considerably less agreement regarding adjuvant treatment after GTR. In Germany, 84\% (47 of 56) of centers recommended surgery alone for initially diagnosed, gross-totally resected WHO Grade II meningioma, ${ }^{127}$ similar to centers in the United Kingdom, in which $80 \%$ made the same recommendation. ${ }^{74} \mathrm{~A}$ number of other reports have suggested that GTR alone is sufficient for these patients. 37,70,72,99,102 Jääskeläinen reported a 38\% 5-year local recurrence rate after GTR and did not find that adjuvant radiation therapy was of utility. ${ }^{52}$ However, no randomized trials have been completed; many of the studies in the liter- ature had small cohorts, used pre-WHO 2000 grading criteria, included patients with newly diagnosed and recurrent tumors, or used radiation therapy doses that were, as will be discussed subsequently, likely too low to be effective.

Employing WHO 2000/2007 criteria and higher EBRT doses, Aghi et al. analyzed 108 patients with atypical meningioma. Following Simpson Grade 1 surgery alone, the 5-year local recurrence rate was $50 \% .^{2} \mathrm{~A}$ more recent report by Komotar et al. reviewed outcomes among 45 patients, each with a gross-totally resected atypical meningioma. Gross-total resection was defined as Simpson Grade 1 or 2, confirmed by postoperative MRI. Thirtytwo $(71 \%)$ of their 45 patients were treated initially with surgery alone and experienced a 5-year actuarial risk of recurrence of $55 \% .{ }^{59}$

The clinical impact of tumor recurrence in patients with atypical meningioma appears to be more significant than in patients with WHO Grade I tumors. Mair et al. found that neither the extent of salvage resection nor the use of radiation therapy was predictive of outcome for patients with recurrent Grade II meningioma. ${ }^{72}$ Aghi et al. reported a 10 -year disease-specific survival rate of $69 \%$ after first recurrence. ${ }^{2}$ With a median follow-up of 44.1 months, the study of Komotar and colleagues noted crude overall survival of $69.2 \%$ following first recurrence, very similar to the study of Aghi et al., ${ }^{2}$ and concluded that recurrences resulted in shortened overall survival, as well as additional treatment burden. ${ }^{59}$

\section{Radiation Therapy}

Various forms of radiation therapy have been used for Grade II meningioma following STR, including SRS 5,55 , ${ }_{129,133}$ and EBRT. ${ }^{2,8,16,18,49,80}$ Even following GTR, many have advocated radiation therapy for these patients, $2,18,41,48,49$, 100,156 but others recommend observation. ${ }^{37,72,102}$ Irradiation is also commonly employed as a primary modality for some meningiomas, but as there was no pathological confirmation it is unclear how many were WHO Grade II tumors. The determination of grade requires tissue confirmation, and there are very limited data on primary radiation therapy after biopsy alone. 
Achieving local control for patients with atypical meningiomas is an important end point with radiation therapy and appears to be paramount. As aforementioned, Aghi et al. reported a $69 \%$ 10-year disease-specific survival rate after first recurrence. ${ }^{2}$ Skeie and colleagues found that 6 of 7 patients with recurrence died of disease at a mean of 25 months after regrowth. ${ }^{129}$ Stafford et al. noted that patients with prior surgery or EBRT fared worse, and that patients with recurrent atypical tumors continued to exhibit worse cause-specific survival despite aggressive salvage therapy. ${ }^{133}$

\section{Stereotactic Radiosurgery}

Reports of SRS for Grade II meningiomas are, with near exclusivity, in the settings of STR or recurrence, mostly the latter. Table 6 summarizes 8 series involving SRS for atypical meningiomas. Reported local control at 2 years and beyond spans a wide range, from $0 \%$ up to $90 \%$, with most in the $50 \%$ to $80 \%$ range. These studies suggest that dose, target volume, and treatment timing are key elements in improving outcomes. Kano et al. reported that 5-year PFS for lesions treated using less than $20 \mathrm{~Gy}$ was $29.4 \%$, compared with $68 \%$ for those receiving $20 \mathrm{~Gy}$ $(\mathrm{p}=0.0139) .{ }^{55}$ However, Stafford et al. identified a 5-year local control rate of $68 \%$ using a moderately lower dose (median $16 \mathrm{~Gy}$, range 12-36 Gy), and found no clear correlation between SRS dose and local control. ${ }^{133}$

Attia and colleagues, studying dose and conformality index (treatment volume $\div$ tumor volume) in residual or recurrent Grade II tumors, shed further light on this issue. Their median dose was 14 Gy (range 12-18 Gy). Local recurrence, defined as within $2 \mathrm{~cm}$ of the original tumor margin, developed in $48 \%$ at 5 years, with a median time to recurrence of 25 months. When the conformality index was considered, margin dose was not predictive of local control. ${ }^{5}$ The mean conformality index was 1.7 in the patients who experienced recurrence and 4.6 in those who did not $(\mathrm{p}=0.038)$. This raises the possibility that higher doses in some studies ${ }^{55}$ might, in part, be a proxy for a larger conformality index.

This finding is supported by other studies showing that atypical meningiomas may recur outside of the SRS target, yet inside the resection bed. Huffmann et al. treated 15 patients with a median dose of 16 Gy. At 18 to 36 months, 9 were progression free, for a crude local control rate of $60 \%$. Six $(40 \%)$ progressed, $1(17 \%)$ in field, but all within the surgical approach or resection bed. ${ }^{48}$ Choi et al. reviewed 25 patients with Grade II meningiomas, with a median marginal dose of $22 \mathrm{~Gy}$ (range 16-30 Gy) in 1-4 fractions (median 1). Recurrence was identified in 9 patients: 3 (33\%) within the targeted region (local failure), 5 (56\%) elsewhere in the resection bed (regional failure), and 1 (11\%) locoregionally. ${ }^{13}$ These findings suggest that, for atypical meningioma, a volume beyond the residual or recurrent enhancement is at risk, and that this includes the entire tumor and resection bed. Further patterns of failure analyses will help define the best approaches to target definition.

Timing of treatment may also influence outcome. Choi et al. showed improved local control with immediate postoperative SRS (within 6 months of surgery) as opposed to SRS at recurrence or progression. ${ }^{13}$ Harris and colleagues, defining "late" as after radiographic progression and "early" as after craniotomy without imaging evidence of progression, found a median time to neurological progression of 15 months after "late" SRS, compared with 61 months with "early" treatment. ${ }^{41}$

Multisession SRS has also been used for Grade II meningioma, often for larger or critically located tumors, involving for instance the anterior optic apparatus, or the sagittal sinus where edema more likely occurs after single-fraction SRS. ${ }^{17,33,144}$ Local control results have been essentially equivalent to single-fraction therapy, ${ }^{17}$ possibly with a lower risk of side effects. ${ }^{17,33,144}$ Vernimmen et al. reported on multifraction SRS using protons. With a mean follow-up of 40 months, $88 \%$ of the patients remained under radiological control. With the multifraction approach, these investigators were able to treat larger tumors, up to $63 \mathrm{~cm}^{3} .150$ Presently, multifraction SRS data specific to atypical meningioma is limited, and its role and proper dose-volume constraints remain important research questions.

\section{Fractionated EBRT}

Several investigators have reviewed EBRT for atypical meningioma. Some have recommended EBRT irrespective of resection extent, ${ }^{18,49,156}$ but others have questioned its benefit. Goyal et al. reported local control of $87 \%$ at 5 and 10 years among 22 patients. EBRT was used in 8 patients, with a median dose of $54 \mathrm{~Gy}$, but did not significantly affect outcome.${ }^{37}$ Hoffman and colleagues identified 10 patients with Grade II meningioma; the postoperative recurrence rate was 50\%. They suggested a benefit to EBRT, especially when radical surgery could not be achieved, and recommended a higher total dose of $60 \mathrm{~Gy} .{ }^{47}$

Aghi et al. published an analysis of 108 patients with atypical meningioma and Simpson Grade I resection. One hundred (93\%) underwent surgery alone, and $8(7 \%)$ underwent surgery as well as EBRT (mean 60.2 Gy). The target volume was described as $1 \mathrm{~cm}$ beyond the resection bed. Five-year recurrence after GTR alone was $45 \%$, but $0 \%$ following surgery with EBRT. This difference did not reach statistical significance $(\mathrm{p}=0.1)$, perhaps due to the relatively small number of events. These investigators assessed the clinical consequences of recurrence and found that all 30 patients with recurrence ultimately received either EBRT or SRS, and 73\% underwent repeat surgery, with a mean number of craniotomies of 2.7. Only 1 meningioma had transformed to WHO Grade III, but at 7 years $33 \%$ of the patients had died as a result of recurrence. $^{2}$

Similarly, Komotar et al. reported on 45 patients with atypical meningioma who received a Simpson Grade 1 or 2 resection. Thirty-two underwent GTR alone and 13 had GTR with EBRT (median 59.4 Gy), to a target described as the tumor cavity as well as a 0.5 to $1.0 \mathrm{~cm}$ margin. After surgery alone, 13 patients (41\%) experienced recurrence at a median of 19 months. After GTR and EBRT, 1 patient $(8 \%)$ experienced recurrence at 52.5 months. Following GTR alone versus GTR and EBRT, the respective 6 -year actuarial recurrence risks were $65 \%$ versus $20 \%$ (p $=0.085) .{ }^{59}$ Other recent analyses have supported EBRT in this setting. Park et al. reported 5-year PFS rates of 46.4\% 


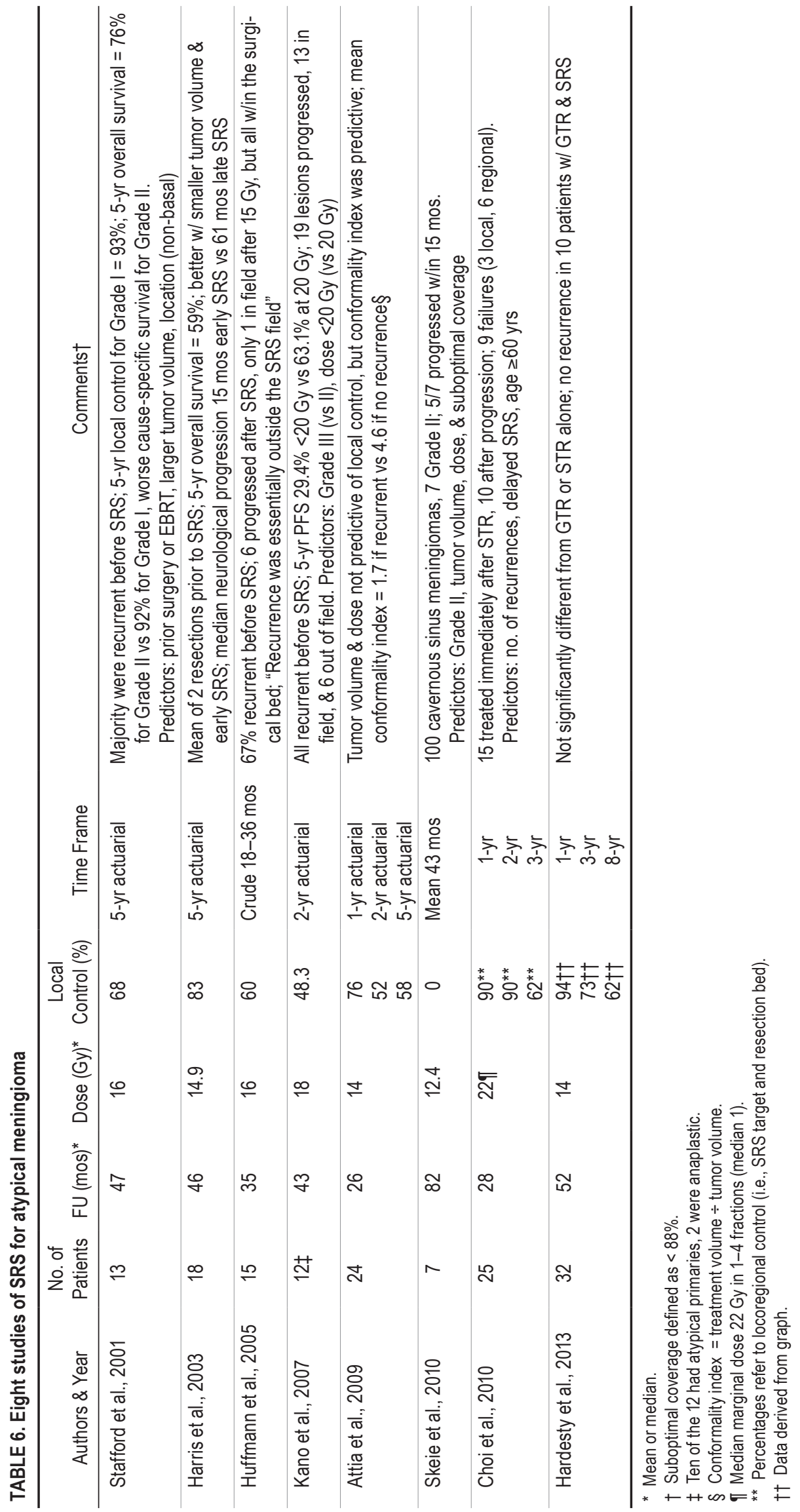


with GTR alone, $77.9 \%$ with GTR and EBRT, $0 \%$ with STR alone, and 55.6\% for STR and EBRT. Progressionfree survival was improved by EBRT, regardless of the extent of resection. ${ }^{100}$

Others have reached different conclusions. Mair et al. suggested that EBRT was not appropriate following GTR, and advised SRS rather than EBRT following STR. ${ }^{72}$ In spite of this contention, their report did confirm that EBRT improved PFS. Comparing surgery to surgery with EBRT, 4-year PFS rates were $13 \%$ following surgery alone versus $72 \%$ with surgery and EBRT $(p=0.043)$. These results were not stratified by extent of resection, and Mair et al. used a relatively low mean EBRT dose of 51.8 Gy in 28 fractions. ${ }^{72}$ Hardesty and colleagues reported improved outcomes with GTR but no significant improvement in recurrence rate with radiation therapy (either EBRT or SRS) following "aggressive microsurgical resection" of an atypical meningioma. Gross-total resection, defined as Simpson Grade 1 or 2, was achieved in 58\% of patients. Appreciating the lack of statistical significance, it is notable that no patient in this study treated with a GTR and postoperative radiation therapy experienced recurrence, with actuarial data extending 7 to 9 years. ${ }^{40}$ In this series, the number and length of follow-up of patients managed with GTR and radiation therapy was limited. Their median radiation therapy dose, 54 Gy with 1.8- to 2.0-Gy fractions, as discussed below, may be lower than optimal, but even with this dosing, there were no recurrences in patients treated with GTR and radiation therapy.

A Surveillance, Epidemiology, and End Results (SEER)-based analysis by Stessin et al. reviewed 657 patients treated for nonbenign meningioma from 1988 to 2007..$^{135}$ Two hundred forty four $(37 \%)$ received adjuvant EBRT. After controlling for WHO grade (II vs III), tumor size, extent of resection, and date of diagnosis (i.e., considering the $2000 \mathrm{WHO}$ reclassification), EBRT was not found to impart a survival or disease-specific survival benefit. Paradoxically, they found significantly lower survival for patients receiving adjuvant EBRT than for those receiving no radiation, possibly reflecting a treatment selection bias for patients with poor overall prognosis. Stessin et al. did not analyze local control, and did not factor in EBRT doses or target definition parameters ${ }^{135}$ this may be of critical importance because higher EBRT doses appear to improve outcome for Grade II meningioma.

Park et al. found an improved PFS using a mean dose of 61.2 Gy. ${ }^{100}$ Aghi et al. observed no local recurrences with 59.4 to $61.2 \mathrm{~Gy},{ }^{2}$ and Komotar et al. had numerically better outcomes with a median EBRT dose of $59.4 \mathrm{~Gy}$. The RTOG trial (no. 0539), which recently completed accrual, used $54 \mathrm{~Gy}$ in 30 fractions for newly diagnosed atypical meningioma following GTR, and 60 Gy in 30 fractions following STR or for recurrent Grade II tumors of any resection extent. The completed EORTC trial (no. 2204226042) employed 60 Gy following a GTR and added a 10Gy boost after STR. These trials will ultimately provide important guidance regarding dose escalation for atypical meningioma.

Studies of proton radiotherapy further illuminate questions of dose. Hug et al. published results of 15 patients with atypical meningioma. Approximately half of all patients re- ceived EBRT with photons and half combined photons and protons, with total doses from 40 to 72 cobalt gray equivalents (CGEs). Local control was significantly improved with doses greater than $60 \mathrm{CGE}$, with a 5-year local control rate of $90 \%$ with greater than $60 \mathrm{CGE}$, and $0 \%$ with less than 60 CGE. These authors noted improved results with combined photon and proton therapy, but this was not an independent factor, rather a reflection of higher doses with the use of protons. ${ }^{49}$ Boskos et al. published outcomes on 24 patients with high-grade meningiomas, typically treated following STR. Nineteen meningiomas (79\%) were WHO Grade II. Cause-specific survival at 5 years was $80 \%$ with greater than 60 Gy compared with $24 \%$ with less than 60 Gy $(\mathrm{p}=0.01)$. There was a trend toward further improvement with doses greater than $65 \mathrm{~Gy}(\mathrm{p}=0.06){ }^{8}$

Optimal dosing regimens, and choices among varying radiation modalities, are important matters for further study. Dose escalation may have a role in treating high-grade meningioma, but caution with dose escalation is warranted. Using accelerated hyperfractionated EBRT with or without an SRS boost, Katz et al. found a high rate of complications with no improvement in tumor control. ${ }^{56}$ Future research on radiation therapy dosing and other critical issues will be strengthened by uniform adoption of WHO grading standards and by studies that stratify patients into de novo and recurrent categories.

\section{WHO Grade III (Anaplastic/Malignant) Meningioma}

Less than $3 \%$ of newly diagnosed meningiomas are WHO Grade III (also termed anaplastic or malignant). Consequently, there are only about 300 newly diagnosed anaplastic meningiomas per year in the US. ${ }^{47}$ With such rarity, firm conclusions regarding optimal treatment are problematic.

These are aggressive tumors with considerably poorer local control and overall survival than lower grade meningiomas. In studies used to determine WHO grading, median overall survival in patients with these tumors has been less than 2 to 3 years (Fig. 1). ${ }^{108,109}$ There is little discrepancy in recommendations for aggressive treatment, which typically includes surgery and radiation therapy, but regarding the required extent of surgery, the preferred type of radiation therapy, and its dosing and target volume constraints, treatment remains controversial. Even with aggressive management, local control remains difficult to attain, and metastasis, although uncommon, can occur. Improved treatment paradigms are needed.

\section{Surgery}

In most cases of aggressive meningioma, surgery serves as the first-line therapy and helps establish a diagnosis. As is the case with lower grade meningiomas, recurrence corresponds to the extent of tumor removal. ${ }^{27,37,99,108}$ However, the success of surgery alone has not been satisfactory. Jääskeläinen et al. reported a 5-year recurrence rate of 78\% following GTR for patients with anaplastic meningioma, less than half of whom received any adjuvant therapy. ${ }^{52}$ Among patients with malignant histology treated with surgery alone, Dziuk et al. encountered a 5-year PFS of 28\% after GTR, and 0\% after STR. ${ }^{27}$ Most investigators now recommend adjuvant therapy. ${ }^{28,113,138}$ 
When a clear plane between the tumor and surrounding normal structures can be identified, GTR remains the goal of surgery for anaplastic meningioma. ${ }^{140}$ Sughrue et al. recently analyzed resection extent for patients with WHO Grade III meningioma. All patients were also referred for postoperative EBRT. They found that heroic surgical efforts did not improve survival, and even compromised neurological outcome. Specifically, they found improved overall survival with near-total resection as opposed to GTR; near-total resection implied greater than $90 \%$ tumor removal. ${ }^{140}$

Surgery appears to be beneficial at recurrence as well. Correcting for other prognostic factors, Sughrue et al. found a survival benefit from repeat operation, with median survivals of 53 months with salvage surgery versus 25 months without $(\mathrm{p}=0.02)$. All patients received EBRT, and some also received radiosurgery or brachytherapy. As with their patients in the de novo setting, near-total resection resulted in superior median survival compared with GTR (77 vs 42 months, respectively; $p=0.005$ ). ${ }^{140}$ In contrast, other investigators have found that the mode of salvage therapy for patients with WHO Grade III meningiomas did not significantly affect time to subsequent progression. ${ }^{122}$

\section{Radiation Therapy}

There are no randomized trials to document the efficacy of multimodality therapy for patients with malignant meningioma, but retrospective studies, using varying definitions of anaplasia, have reported measurable benefits. ${ }^{18,27,80,122,130}$ As documented in Table 7, both EBRT and SRS have been used. Outcomes vary, perhaps in part by treatment technique, but also in relation to the extent of surgery, the histological grading standards employed, the extent and type of follow-up, and the timing of radiation treatment.

\section{Stereotactic Radiosurgery}

Some authors have argued that SRS is not indicated for malignant meningioma, ${ }^{85}$ but several studies have reported outcomes with SRS (Table 7). Kondziolka et al. treated 29 WHO Grade III patients with postoperative SRS, using a mean margin dose of $14 \mathrm{~Gy}$, and found PFS rates of $17 \%$ at 15 months and 9\% (extrapolated from graph) at 5 years. ${ }^{62}$ In a separate publication of convexity meningioma, the same group treated 5 WHO Grade III patients. With follow-up extending to 47 months, none maintained local control, and 4 of 6 died of tumor progression. ${ }^{61}$

El-Khatib et al. reported 7 patients with WHO Grade III meningioma, using a 14 Gy margin dose. ${ }^{28}$ They found considerably higher rates of PFS, $57 \%$ at 3 years and $43 \%$ at 10 years. This study used similar tumor margin doses to Kondziolka et al. The mean target volumes were modestly smaller in the El-Khatib et al. study $\left(4.8 \mathrm{vs} 7.4 \mathrm{~cm}^{3}\right)$. Both studies included newly diagnosed and recurrent tumors. The Kondziolka study graded tumors based upon "previous histopathology" (often diagnosed before the advent of the WHO criteria), whereas El-Khatib et al. used the WHO 2007 criteria. These differences in diagnostic criteria may play a role in accounting for the differences in results.

Pollock and colleagues recently published their expe- rience with 50 WHO Grade II or III patients, treated in both the de novo and salvage settings. Thirteen patients had anaplastic meningioma. Their median treatment volume was larger at $14.6 \mathrm{~cm}^{3}$, and the median dose was modestly higher at $15 \mathrm{~Gy}$. Disease-specific survival rates at 1 and 5 years for the WHO Grade III patients were 69\% and $27 \%$, respectively. These investigators did not specify PFS for malignant meningioma alone, but for their entire group of 50 high-grade tumors, PFS at 1 year was $76 \%$, and at 5 years was $40 \%$. For patients who had failed prior EBRT, PFS was lower, i.e., $19 \%$ at 3 years. ${ }^{114}$

\section{Fractionated EBRT}

The early experiences of Milosevic et al. ${ }^{80}$ and Dziuk et al. ${ }^{27}$ provide evidence of benefit from surgery followed by EBRT, and indeed for the use of EBRT initially rather than at progression, now accepted as a standard approach for anaplastic meningiomas. Milosevic et al. found that patients who received $<50$ Gy experienced inferior causespecific survival, as did those treated before 1975 (i.e., before CT-based planning). ${ }^{80}$ Dziuk et al. found that EBRT improved 5-year PFS from 50\% to $80 \%$ compared with surgery alone. When EBRT was added following initial resection, 5-year PFS significantly improved from 15\% to $80 \%$. They recommended a total EBRT dose of 6000 cGy "be administered coincident with an initial complete resection, with a $4 \mathrm{~cm}$ margin for the initial $5000 \mathrm{cGy} .{ }^{27}$

The use and extent of a margin in radiation therapy treatment planning is a topic of particular interest when comparing EBRT and SRS for malignant meningiomas. With SRS, Pollock et al. described tumor progression "away from the original irradiated tumor" in $30 \%$ of patients with atypical or anaplastic meningioma, occurring at a median of 15 months after SRS. Most (80\%) were marginal, meaning "adjacent to the irradiated tumor."113 Analyzing SRS and stereotactic EBRT for recurrent highgrade meningioma, Mattozo et al. found that $77 \%$ of recurrences were within the original resection cavity, and recommended that "the whole cavity receive radiation therapy," with an SRS boost to the recurrent nodule if desired. They suggested that EBRT to treat the entire tumor cavity after initial surgery may be appropriate to reduce the risk of any relapse..$^{75}$

Indeed, the timing of radiation therapy appears to be an important factor. Some studies have shown modest benefit from irradiation in the recurrent setting, ${ }^{27}$ but others have suggested little or no improvement from salvage radiation therapy ${ }^{75,122,138}$ Dziuk et al. reported that EBRT improved local control with malignant meningioma compared with surgery alone. Even in the recurrent group, 2-year PFS improved from $50 \%$ to $89 \%(\mathrm{p}=0.002)$ with EBRT, although it had no impact at 5 years. ${ }^{27}$ Following initial resection, several investigators have found outcome improvement with radiation therapy (Table 7)..$^{27,41,80,122}$

Other radiation therapy factors may play important roles. As with atypical meningioma, higher radiation therapy doses appear to improve local tumor control for patients with malignant histology. Reviewing WHO Grade II and III patients, Milosevic found a 5-year cause-specific survival of $42 \%$ with at least 50 Gy versus $0 \%$ with less than 50 Gy ${ }^{80}$ With malignant lesions, Goldsmith et 







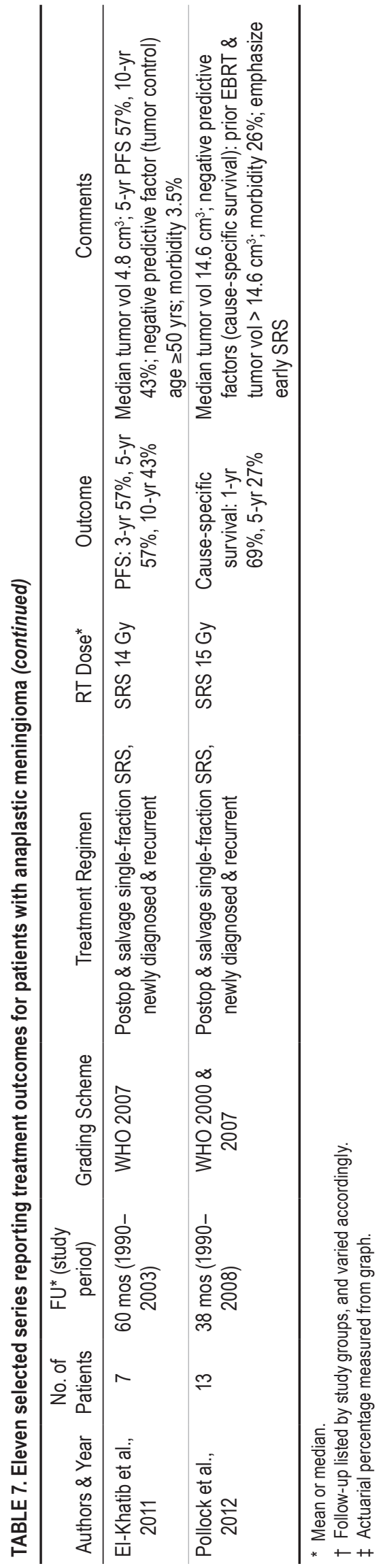

al. reported a 5-year PFS rate of $63 \%$ using greater than 53 Gy versus $17 \%$ with no more than $53 \mathrm{~Gy},{ }^{36}$ and Dziuk et al. recommend a total EBRT dose of $60 \mathrm{~Gy}$, even after GTR. ${ }^{27}$ More recent studies have specifically evaluated doses of this magnitude.

Using either photons or combined photons and protons, DeVries et al. ${ }^{23}$ and Hug et al. ${ }^{49}$ showed dramatic increases in local control and survival with a total dose exceeding $60 \mathrm{~Gy}$. Hug et al., studying a mixed group of WHO Grade II and III meningiomas, identified a 5-year local control rate of $100 \%$ for patients receiving at least $60 \mathrm{CGE}$ versus $0 \%$ with lower doses $(p=0.0006)$; the respective 8 -year values were $33 \%$ and $0 \%$. For the subgroup with malignant meningioma, improved local control corresponded with improved 5- and 8-year overall survival: $87 \%$ with at least $60 \mathrm{CGE}$ and $15 \%$ with less than $60 \mathrm{CGE}$, respectively. ${ }^{49}$ As mentioned with WHO Grade II tumors, some caution is prudent with dose escalation with these tumors. Katz and colleagues found no benefit from accelerated hyperfractionated radiation therapy, on occasion with an SRS boost, but did encounter unacceptable toxicity. ${ }^{56}$

\section{Summary}

Meningiomas are the most common primary intracranial tumors. ${ }^{15}$ The majority are histologically benign (WHO Grade I) but even so can be clinically formidable. Due to a lack of prospective randomized trials, standardized treatment guidelines are difficult to formulate. Furthermore, uniformly applied guidelines have been difficult to achieve given the typical pattern of slow growth and given the availability of several management options. Granting these limitations, a growing body of largely retrospective evidence does permit inferences.

Small, incidental meningiomas can often be carefully observed, as recommended in the National Comprehensive Cancer Network guidelines. For most other patients, GTR remains the benchmark. However, complete tumor removal within the constraints of acceptable morbidity is not always achievable. Many meningiomas arise at or near critical neural or vascular structures or in sites with limited surgical access and can be very challenging for surgeons. ${ }^{136}$ Based on these concerns and on other key features such as WHO grade, clinically significant subgroups of patients cannot be managed successfully by resection alone. When a GTR is not accomplished, postoperative radiation therapy, including SRS or EBRT, is an important consideration. In this setting, numerous studies have indicated improvements in local control, and some have shown significant cause-specific survival advantages as well. In spite of this, controversy remains regarding the most appropriate therapy after STR, particularly as to whether patients should be observed and treated at progression, or treated preemptively. Some patients do well for many years after STR alone, while others progress and develop larger symptomatic tumors more promptly.

Adding further controversy, there is increasing retrospective evidence in support of SRS or EBRT, not only in the adjuvant or salvage setting, but also as primary therapy. The relative efficacy of these approaches has not yet been tested in rigorously designed prospective clinical trials, but results with SRS and EBRT, at least for the ma- 
jority of patients with known or presumed benign (WHO Grade I) meningiomas, have been remarkably similar, whether comparing them to each other or to reported results from surgery. Either SRS or EBRT can be recommended for many patients but not for all. EBRT is suitable for a broader range of patients, whereas excellent outcome with SRS has been realized among more distinct cohorts, taking neurovascular anatomy, location, edema risk, and tumor diameter or volume into careful account. At present, surgery retains a central role in management, acquires tissue for histological and molecular analysis, and promptly addresses rapidly progressive tumors or tumorrelated symptoms. However, with this important caveat, excellent long-term results have been attained using SRS or EBRT administered either adjuvantly or primarily.

Many significant questions remain in the more common setting of benign meningioma, and with highergrade meningioma these uncertainties are magnified. Current data support adjuvant radiation therapy for WHO Grade III meningiomas irrespective of the extent of resection, and for Grade II meningioma at least following STR. Considerable controversy persists for patients with a newly diagnosed and gross-totally resected WHO Grade II meningioma. At present they may be managed with postoperative radiation or with close observation. A randomized clinical trial has been designed to address this very question and is expected to open in the near future. This treatment decision is becoming a more clinically relevant question, as there have been notable increases in the incidence of WHO Grade II meningiomas with broader implementation of the current WHO grading criteria. The RTOG (no. 0539) and EORTC (no. 22042-22062) have recently completed accrual to Phase II clinical trials. From these studies there will likely be clinical outcome analyses to help integrate imaging, operative, central pathology, genotyping, immunohistochemical, microarray, and molecular (serum and urine) correlative findings.

A growing body of investigators are committed to the design and completion of prospective multicenter studies of meningioma and active in the above-mentioned studies and in the development of other trials. A companion article will evaluate the role of systemic therapies for patients with meningioma. Additionally, RANO is currently completing a manuscript proposing standardized end points and response criteria, providing investigators an opportunity to design trials and publish outcomes in a more uniform and consonant fashion.

\section{References}

1. Adegbite AB, Khan MI, Paine KWE, Tan LK: The recurrence of intracranial meningiomas after surgical treatment. J Neurosurg 58:51-56, 1983

2. Aghi MK, Carter BS, Cosgrove GR, Ojemann RG, AminHanjani S, Martuza RL, et al: Long-term recurrence rates of atypical meningiomas after gross total resection with or without postoperative adjuvant radiation. Neurosurgery 64:56-60, 2009

3. Akeyson EW, McCutcheon IE: Management of benign and aggressive intracranial meningiomas. Oncology (Williston Park) 10:747-759, 1996

4. Asgharian B, Chen YJ, Patronas NJ, Peghini PL, Reynolds JC, Vortmeyer A, et al: Meningiomas may be a component tumor of multiple endocrine neoplasia type 1. Clin Cancer Res 10:869-880, 2004

5. Attia A, Chan M, Seif D, Russell GB, Bourland JD, Deguzman A, et al: Treatment of atypical meningiomas with Gamma Knife Radiosurgery: the role of conformality index and margin dose. Int J Radiat Oncol Biol Phys 75:S226-S227, 2009 (Abstract)

6. Barbaro NM, Gutin PH, Wilson CB, Sheline GE, Boldrey EB, Wara WM: Radiation therapy in the treatment of partially resected meningiomas. Neurosurgery 20:525-528, 1987

7. Bledsoe JM, Link MJ, Stafford SL, Park PJ, Pollock BE: Radiosurgery for large-volume $(>10 \mathrm{~cm} 3)$ benign meningiomas. J Neurosurg 112:951-956, 2010

8. Boskos C, Feuvret L, Noel G, Habrand JL, Pommier P, Alapetite $\mathrm{C}$, et al: Combined proton and photon conformal radiotherapy for intracranial atypical and malignant meningioma. Int J Radiat Oncol Biol Phys 75:399-406, 2009

9. Bria C, Wegner RE, Clump DA, Vargo JA, Mintz AH, Heron DE, et al: Fractionated stereotactic radiosurgery for the treatment of meningiomas. J Cancer Res Ther 7:52-57, 2011

10. Central Brain Tumor Registry of the United States: Statistical Report: Primary Brain and Central Nervous System Tumors Diagnosed in the United States in 2004-2006. Hinsdale, IL: CBTRUS, 2010

11. Central Brain Tumor Registry of the United States: Statistical Report: Primary Brain Tumors in the Unites States, 1992-1997. Hinsdale, IL: CBTRUS, 2001

12. Chamoun R, Krisht KM, Couldwell WT: Incidental meningiomas. Neurosurg Focus 31(6):E19, 2011

13. Choi CY, Soltys SG, Gibbs IC, Harsh GR, Jackson PS, Lieberson RE, et al: Cyberknife stereotactic radiosurgery for treatment of atypical (WHO grade II) cranial meningiomas. Neurosurgery 67:1180-1188, 2010

14. Chuang CC, Chang CN, Tsang NM, Wei KC, Tseng CK, Chang JT, et al: Linear accelerator-based radiosurgery in the management of skull base meningiomas. J Neurooncol 66:241-249, 2004

15. Claus EB, Bondy ML, Schildkraut JM, Wiemels JL, Wrensch M, Black PM: Epidemiology of intracranial meningioma. Neurosurgery 57:1088-1095, 2005

16. Coke CC, Corn BW, Werner-Wasik M, Xie Y, Curran WJ Jr: Atypical and malignant meningiomas: an outcome report of seventeen cases. J Neurooncol 39:65-70, 1998

17. Columbo F, Casentini, Cavedon C, Scalchi P, Cora S, Francescon P: Cyberknife radiosurgery for benign meningiomas: short-term results in 199 patients. Neurosurgery 64 (2 Suppl):A7-A13, 2009

18. Condra KS, Buatti JM, Mendenhall WM, Friedman WA, Marcus RB Jr, Rhoton AL: Benign meningiomas: primary treatment selection affects survival. Int J Radiat Oncol Biol Phys 39:427-436, 1997

19. Cushing H: The meningiomas (dural endotheliomas): their source and favoured seats of origin. Brain 45:282-316, 1922

20. Davidson L, Fishback D, Russin JJ, Weiss MH, Yu C, Pagnini PG, et al: Postoperative Gamma Knife surgery for benign meningiomas of the cranial base. Neurosurg Focus 23(4):E6, 2007

21. Davis FG, Kupelian V, Freels S, McCarthy B, Surawicz T: Prevalence estimates for primary brain tumors in the United States by behavior and major histology groups. Neuro Oncol 3:152-158, 2001

22. DeMonte F, Marmor E, Al-Mefty O: Meningiomas, in Kaye A, Laws E (eds): Brain Tumors, ed 2. London: Churchill Livingstone, 2001, pp 719-750

23. DeVries A, Munzenrider JE, Hedley-Whyte T, Hug EB: [The role of radiotherapy in the treatment of malignant meningiomas.] Strahlenther Onkol 175:62-67, 1999 (Ger)

24. DiBiase SJ, Kwok Y, Yovino S, Arena C, Naqvi S, Temple $\mathrm{R}$, et al: Factors predicting local tumor control after gamma 
knife stereotactic radiosurgery for benign intracranial meningiomas. Int J Radiat Oncol Biol Phys 60:1515-1519, 2004

25. dos Santos MA, de Salcedo JBP, Gutiérrez Diaz JA, Calvo FA, Samblás J, Marsiglia H, et al: Long-term outcomes of stereotactic radiosurgery for treatment of cavernous sinus meningiomas. Int J Radiat Oncol Biol Phys 81:1436-1441, 2011

26. Dufour H, Muracciole X, Métellus P, Régis J, Chinot O, Grisoli F: Long-term tumor control and functional outcome in patients with cavernous sinus meningiomas treated by radiotherapy with or without previous surgery: is there an alternative to aggressive tumor removal? Neurosurgery 48:285-296, 2001

27. Dziuk TW, Woo S, Butler EB, Thornby J, Grossman R, Dennis WS, et al: Malignant meningioma: an indication for initial aggressive surgery and adjuvant radiotherapy. J Neurooncol 37:177-188, 1998

28. El-Khatib M, El Majdoub F, Hoevels M, Kocher M, Müller RP, Steiger HJ, et al: Stereotactic LINAC radiosurgery for incompletely resected or recurrent atypical and anaplastic meningiomas. Acta Neurochir (Wien) 153:1761-1767, 2011

29. Eustacchio S, Trummer M, Fuchs I, Schröttner O, Sutter B, Pendl G: Preservation of cranial nerve function following Gamma Knife radiosurgery for benign skull base meningiomas: experience in 121 patients with follow-up of 5 to 9.8 years. Acta Neurochir Suppl 84:71-76, 2002

30. Flannery TJ, Kano H, Lunsford LD, Sirin S, Tormenti M, Niranjan A, et al: Long-term control of petroclival meningiomas through radiosurgery. Clinical article. J Neurosurg 112:957-964, 2010

31. Flickinger JC, Kondziolka D, Maitz AH, Lunsford LD: Gamma knife radiosurgery of imaging-diagnosed intracranial meningioma. Int J Radiat Oncol Biol Phys 56:801-806, 2003

32. Ganz JC, Backlund EO, Thorsen FA: The results of Gamma Knife surgery of meningiomas, related to size of tumor and dose. Stereotact Funct Neurosurg 61 (Suppl 1):23-29, 1993

33. Girvigian MR, Chen JCT, Rahimian J, Miller MJ, Tome M: Comparison of early complications for patients with convexity and parasagittal meningiomas treated with either stereotactic radiosurgery or fractionated stereotactic radiotherapy. Neurosurgery 62 (5 Suppl):A19-A28, 2008

34. Glaholm J, Bloom HJG, Crow JH: The role of radiotherapy in the management of intracranial meningiomas: the Royal Marsden Hospital experience with 186 patients. Int J Radiat Oncol Biol Phys 18:755-761, 1990

35. Goldsmith B: Meningioma, in Leibel S, Phillips T (eds): Textbook of Radiation Oncology. Philadelphia: WB Saunders, 1998, pp 324-340

36. Goldsmith BJ, Wara WM, Wilson CB, Larson DA: Postoperative irradiation for subtotally resected meningiomas. A retrospective analysis of 140 patients treated from 1967 to 1990. J Neurosurg 80:195-201, 1994 (Erratum in J Neurosurg 80:777, 1994)

37. Goyal LK, Suh JH, Mohan DS, Prayson RA, Lee J, Barnett GH: Local control and overall survival in atypical meningioma: a retrospective study. Int J Radiat Oncol Biol Phys 46:57-61, 2000

38. Hamm K, Henzel M, Gross MW, Surber G, Kleinert G, Engenhart-Cabillic R: Radiosurgery/stereotactic radiotherapy in the therapeutical concept for skull base meningiomas. Zentralbl Neurochir 69:14-21, 2008

39. Han JH, Kim DG, Chung HT, Park CK, Paek SH, Kim CY, et al: Gamma knife radiosurgery for skull base meningiomas: long-term radiologic and clinical outcome. Int J Radiat Oncol Biol Phys 72:1324-1332, 2008

40. Hardesty DA, Wolf AB, Brachman DG, McBride HL, Youssef E, Nakaji P, et al: The impact of adjuvant stereotactic radiosurgery on atypical meningioma recurrence following aggressive microsurgical resection. Clinical article. J Neurosurg 119:475-481, 2013
41. Harris AE, Lee JYK, Omalu B, Flickinger JC, Kondziolka D, Lunsford LD: The effect of radiosurgery during management of aggressive meningiomas. Surg Neurol 60:298-305, 2003

42. Hasegawa T, Kida Y, Yoshimoto M, Koike J, Iizuka H, Ishii D: Long-term outcomes of Gamma Knife surgery for cavernous sinus meningioma. J Neurosurg 107:745-751, 2007

43. Hashiba T, Hashimoto N, Izumoto S, Suzuki T, Kagawa N, Maruno M, et al: Serial volumetric assessment of the natural history and growth pattern of incidentally discovered meningiomas. Clinical article. J Neurosurg 110:675-684, 2009

44. Hasseleid BF, Meling TR, Rønning P, Scheie D, Helseth E: Surgery for convexity meningioma: Simpson Grade I as the goal. Clinical article. J Neurosurg 117:999-1006, 2012

45. Hayashi M, Chernov M, Tamura N, Izawa M, Muragaki Y, Iseki $\mathrm{H}$, et al: Gamma knife robotic microradiosurgery for benign skull base meningiomas: tumor shrinkage may depend on the amount of radiation energy delivered per lesion volume (unit energy). Stereotact Funct Neurosurg 89:6-16, 2011

46. Henzel M, Gross MW, Hamm K, Surber G, Kleinert G, Failing T, et al: Stereotactic radiotherapy of meningiomas: symptomatology, acute and late toxicity. Strahlenther Onkol 182:382-388, 2006

47. Hoffman S, Propp JM, McCarthy BJ: Temporal trends in incidence of primary brain tumors in the United States, 19851999. Neuro Oncol 8:27-37, 2006

48. Huffmann BC, Reinacher PC, Gilsbach JM: Gamma knife surgery for atypical meningiomas. J Neurosurg 102 Suppl: 283-286, 2005

49. Hug EB, Devries A, Thornton AF, Munzenride JE, Pardo FS, Hedley-Whyte ET, et al: Management of atypical and malignant meningiomas: role of high-dose, 3D-conformal radiation therapy. J Neurooncol 48:151-160, 2000

50. Iwai Y, Yamanaka K, Ikeda H: Gamma Knife radiosurgery for skull base meningioma: long-term results of low-dose treatment. Clinical article. J Neurosurg 109:804-810, 2008

51. Iwai Y, Yamanaka K, Ishiguro T: Gamma knife radiosurgery for the treatment of cavernous sinus meningiomas. Neurosurgery 52:517-524, 2003

52. Jääskeläinen J: Seemingly complete removal of histologically benign intracranial meningioma: late recurrence rate and factors predicting recurrence in 657 patients. A multivariate analysis. Surg Neurol 26:461-469, 1986

53. Jalali R, Loughrey C, Baumert B, Perks J, Warrington AP, Traish D, et al: High precision focused irradiation in the form of fractionated stereotactic conformal radiotherapy (SCRT) for benign meningiomas predominantly in the skull base location. Clin Oncol (R Coll Radiol) 14:103-109, 2002

54. Jensen R, Lee J: Predicting outcomes of patients with intracranial meningiomas using molecular markers of hypoxia, vascularity, and proliferation. Neurosurgery 71:146-156, 2012

55. Kano H, Takahashi JA, Katsuki T, Araki N, Oya N, Hiraoka $\mathrm{M}$, et al: Stereotactic radiosurgery for atypical and anaplastic meningiomas. J Neurooncol 84:41-47, 2007

56. Katz TS, Amdur RJ, Yachnis AT, Mendenhall WM, Morris CG: Pushing the limits of radiotherapy for atypical and malignant meningioma. Am J Clin Oncol 28:70-74, 2005

57. King DL, Chang CH, Pool JL: Radiotherapy in the management of meningiomas. Acta Radiol Ther Phys Biol 5:26-33, 1966

58. Kollová A, Liscák R, Novotný J Jr, Vladyka V, Simonová G, Janousková L: Gamma Knife surgery for benign meningioma. J Neurosurg 107:325-336, 2007

59. Komotar RJ, Iorgulescu JB, Raper DMS, Holland EC, Beal $\mathrm{K}$, Bilsky $\mathrm{MH}$, et al: The role of radiotherapy following gross-total resection of atypical meningiomas. Clinical article. J Neurosurg 117:679-686, 2012

60. Kondziolka D, Flickinger JC, Perez B: Judicious resection 
and/or radiosurgery for parasagittal meningiomas: outcomes from a multicenter review. Neurosurgery 43:405-414, 1998

61. Kondziolka D, Madhok R, Lunsford LD, Mathieu D, Martin JJ, Niranjan A, et al: Stereotactic radiosurgery for convexity meningiomas. Clinical article. J Neurosurg 111:458-463, 2009

62. Kondziolka D, Mathieu D, Lunsford LD, Martin JJ, Madhok $R$, Niranjan A, et al: Radiosurgery as definitive management of intracranial meningiomas. Neurosurgery 62:53-60, 2008

63. Korah MP, Nowlan AW, Johnstone PA, Crocker IR: Radiation therapy alone for imaging-defined meningiomas. Int J Radiat Oncol Biol Phys 76:181-186, 2010

64. Kreil W, Luggin J, Fuchs I, Weigl V, Eustacchio S, Papaefthymiou G: Long term experience of gamma knife radiosurgery for benign skull base meningiomas. J Neurol Neurosurg Psychiatry 76:1425-1430, 2005

65. Lee JY, Niranjan A, McInerney J, Kondziolka D, Flickinger JC, Lunsford LD: Stereotactic radiosurgery providing longterm tumor control of cavernous sinus meningiomas. J Neurosurg 97:65-72, 2002

66. Lin NU, Lee EQ, Aoyama H, Barani IJ, Baumert BG, Brown $\mathrm{PD}$, et al: Challenges relating to solid tumour brain metastases in clinical trials, part 1: patient population, response, and progression. A report from the RANO group. Lancet Oncol 14:e396-e406, 2013

67. Lin NU, Wefel JS, Lee EQ, Schiff D, van den Bent MJ, Soffietti R, et al: Challenges relating to solid tumour brain metastases in clinical trials, part 2: neurocognitive, neurological, and quality-of-life outcomes. A report from the RANO group. Lancet Oncol 14:e407-e416, 2013

68. Litré CF, Colin P, Noudel R, Peruzzi P, Bazin A, Sherpereel $\mathrm{B}$, et al: Fractionated stereotactic radiotherapy treatment of cavernous sinus meningiomas: a study of 100 cases. Int J Radiat Oncol Biol Phys 74:1012-1017, 2009

69. Mahadevan A, Floyd S, Wong E, Chen C, Kasper E: Clinical outcome after hypofractionated stereotactic radiotherapy (HSRT) for benign skull base tumors. Comput Aided Surg 16:112-120, 2011

70. Mahmood A, Caccamo DV, Tomecek FJ, Malik GM: Atypical and malignant meningiomas: a clinicopathological review. Neurosurgery 33:955-963, 1993

71. Mahmood A, Qureshi NH, Malik GM: Intracranial meningiomas: analysis of recurrence after surgical treatment. Acta Neurochir (Wien) 126:53-58, 1994

72. Mair R, Morris K, Scott I, Carroll TA: Radiotherapy for atypical meningiomas. Clinical article. J Neurosurg 115:811-819, 2011

73. Marchetti M, Bianchi S, Milanesi I, Bergantin A, Bianchi L, Broggi G, et al: Multisession radiosurgery for optic nerve sheath meningiomas - an effective option: preliminary results of a single-center experience. Neurosurgery 69:11161123,2011

74. Marcus HJ, Price SJ, Wilby M, Santarius T, Kirollos RW: Radiotherapy as an adjuvant in the management of intracranial meningiomas: are we practising evidence-based medicine? Br J Neurosurg 22:520-528, 2008

75. Mattozo CA, De Salles AAF, Klement IA, Gorgulho A, McArthur D, Ford JM, et al: Stereotactic radiation treatment for recurrent nonbenign meningiomas. J Neurosurg 106:846-854, 2007

76. McDermott MW, Wilson CB: Meningiomas, in Youmans JR (ed): Neurological Surgery, ed 4. Philadelphia: WB Saunders, 1996, pp 2782-2825

77. Metellus P, Batra S, Karkar S, Kapoor S, Weiss S, Kleinberg $\mathrm{L}$, et al: Fractionated conformal radiotherapy in the management of cavernous sinus meningiomas: long-term functional outcome and tumor control at a single institution. Int J Radiat Oncol Biol Phys 78:836-843, 2010

78. Milker-Zabel S, Zabel A, Schulz-Ertner D, Schlegel W, Wannenmacher M, Debus J: Fractionated stereotactic radio- therapy in patients with benign or atypical intracranial meningioma: long-term experience and prognostic factors. Int J Radiat Oncol Biol Phys 61:809-816, 2005

79. Milker-Zabel S, Zabel-du Bois A, Huber P, Schlegel W, Debus $\mathrm{J}$ : Intensity-modulated radiotherapy for complex-shaped meningioma of the skull base: long-term experience of a single institution. Int J Radiat Oncol Biol Phys 68:858-863, 2007

80. Milosevic MF, Frost PJ, Laperriere NJ, Wong CS, Simpson WJ: Radiotherapy for atypical or malignant intracranial meningioma. Int J Radiat Oncol Biol Phys 34:817-822, 1996

81. Minniti G, Clarke E, Cavallo L, Osti MF, Esposito V, Cantore G, et al: Fractionated stereotactic conformal radiotherapy for large benign skull base meningiomas. Radiat Oncol 6:3642,2011

82. Minniti G, Traish D, Ashley S, Gonsalves A, Brada M: Risk of second brain tumor after conservative surgery and radiotherapy for pituitary adenoma: update after an additional 10 years. J Clin Endocrinol Metab 90:800-804, 2005

83. Miralbell R, Linggood RM, de la Monte S, Convery K, Munzenrider JE, Mirimanoff RO: The role of radiotherapy in the treatment of subtotally resected benign meningiomas. J Neurooncol 13:157-164, 1992

84. Mirimanoff RO, Dosoretz DE, Linggood RM, Ojemann RG, Martuza RL: Meningioma: analysis of recurrence and progression following neurosurgical resection. J Neurosurg 62:18-24, 1985

85. Modha A, Gutin PH: Diagnosis and treatment of atypical and anaplastic meningiomas: a review. Neurosurgery 57:538550,2005

86. Morimoto M, Yoshioka Y, Shiomi H, Isohashi F, Konishi K, Kotsuma T, et al: Significance of tumor volume related to peritumoral edema in intracranial meningioma treated with extreme hypofractionated stereotactic radiation therapy in three to five fractions. Jpn J Clin Oncol 41:609-616, 2011

87. Morokoff AP, Zauberman J, Black PM: Surgery for convexity meningiomas. Neurosurgery 63:427-434, 2008

88. Nakamura M, Roser F, Michel J, Jacobs C, Samii M: The natural history of incidental meningiomas. Neurosurgery 53:62-71, 2003

89. Nakasu S, Nakasu Y, Fukami T, Jito J, Nozaki K: Growth curve analysis of asymptomatic and symptomatic meningiomas. J Neurooncol 102:303-310, 2011

90. Narayan S, Cornblath WT, Sandler HM, Elner V, Hayman JA: Preliminary visual outcomes after three-dimensional conformal radiation therapy for optic nerve sheath meningioma. Int J Radiat Oncol Biol Phys 56:537-543, 2003

91. National Comprehensive Cancer Network: NCCN Clinical Practice Guidelines in Oncology (NCCN Guidelines ${ }^{\circledR}$ ). Central Nervous System Cancers, Version 1.2014. NCCN, 2014

92. Nicolato A, Foroni R, Alessandrini F, Maluta S, Bricolo A, Gerosa M: The role of Gamma Knife radiosurgery in the management of cavernous sinus meningiomas. Int J Radiat Oncol Biol Phys 53:992-1000, 2002

93. Niranjan A, Kondziolka D, Lunsford LD: Neoplastic transformation after radiosurgery or radiotherapy: risk and realities. Otolaryngol Clin North Am 42:717-729, 2009

94. Nutting C, Brada M, Brazil L, Sibtain A, Saran F, Westbury $\mathrm{C}$, et al: Radiotherapy in the treatment of benign meningioma of the skull base. J Neurosurg 90:823-827, 1999

95. Ohba S, Kobayashi M, Horiguchi T, Onozuka S, Yoshida K, Ohira T, et al: Long-term surgical outcome and biological prognostic factors in patients with skull base meningiomas. Clinical article. J Neurosurg 114:1278-1287, 2011

96. Onodera S, Aoyama H, Katoh N, Taguchi H, Yasuda K, Yoshida D, et al: Long-term outcomes of fractionated stereotactic radiotherapy for intracranial skull base benign meningiomas in single institution. Jpn J Clin Oncol 41:462-468, 2011 
97. Oya S, Kawai K, Nakatomi H, Saito N: Significance of Simpson grading system in modern meningioma surgery: integration of the grade with MIB-1 labeling index as a key to predict the recurrence of WHO Grade I meningiomas. Clinical article. J Neurosurg 117:121-128, 2012

98. Oya S, Kim SH, Sade B, Lee JH: The natural history of intracranial meningiomas. Clinical article. J Neurosurg 114:1250-1256, 2011

99. Palma L, Celli P, Franco C, Cervoni L, Cantore G: Longterm prognosis for atypical and malignant meningiomas: a study of 71 surgical cases. J Neurosurg 86:793-800, 1997

100. Park H, Kim I, Jung H: Atypical meningioma: outcome and prognostic factors. Int J Radiat Oncol Biol Phys 75:S238, 2009 (Abstract)

101. Paulsen F, Doerr S, Wilhelm H, Becker G, Bamberg M, Classen J: Fractionated stereotactic radiotherapy in patients with optic nerve sheath meningioma. Int J Radiat Oncol Biol Phys 82:773-778, 2012

102. Pearson BE, Markert JM, Fisher WS, Guthrie BL, Fiveash JB, Palmer CA, et al: Hitting a moving target: evolution of a treatment paradigm for atypical meningiomas amid changing diagnostic criteria. Neurosurg Focus 24(5):E3, 2008

103. Peele KA, Kennerdell JS, Maroon JC, Kalnicki S, Kazim $\mathrm{M}$, Gardner T, et al: The role of postoperative irradiation in the management of sphenoid wing meningiomas. A preliminary report. Ophthalmology 103:1761-1767, 1996

104. Perry A: Meningiomas, in McLendon RE, Rosenblum MK, Bigner DD (eds): Russell \& Rubinstein's Pathology of Tumors of the Nervous System, ed 7. London: Hodder Arnold, 2006, pp 427-474

105. Perry A, Dehner LP: Meningeal tumors of childhood and infancy. An update and literature review. Brain Pathol 13:386-408, 2003

106. Perry A, Giannini C, Raghavan R, Scheithauer BW, Banerjee R, Margraf L, et al: Aggressive phenotypic and genotypic features in pediatric and NF2-associated meningiomas: a clinicopathologic study of 53 cases. J Neuropathol Exp Neurol 60:994-1003, 2001

107. Perry A, Louis DN, Scheithauer BW, Budka H, von Deimling A: Meningeal tumours, in Louis DN, Ohgaki H, Wiestler OD, et al (eds): WHO Classification of Tumours of the Central Nervous System, ed 4. Lyon: IARC Press, 2007, pp 164-172

108. Perry A, Scheithauer BW, Stafford SL, Lohse CM, Wollan PC: "Malignancy" in meningiomas: a clinicopathologic study of 116 patients, with grading implications. Cancer 85:2046-2056, 1999

109. Perry A, Stafford SL, Scheithauer BW, Suman VJ, Lohse CM: Meningioma grading: an analysis of histologic parameters. Am J Surg Pathol 21:1455-1465, 1997

110. Pirzkall A, Debus J, Haering P, Rhein B, Grosser KH, Höss A, et al: Intensity modulated radiotherapy (IMRT) for recurrent, residual, or untreated skull-base meningiomas: preliminary clinical experience. Int J Radiat Oncol Biol Phys 55:362-372, 2003

111. Pollock BE, Stafford SL: Results of stereotactic radiosurgery for patients with imaging defined cavernous sinus meningiomas. Int J Radiat Oncol Biol Phys 62:14271431, 2005

112. Pollock BE, Stafford SL, Link MJ: Gamma knife radiosurgery for skull base meningiomas. Neurosurg Clin N Am 11:659-666, 2000

113. Pollock BE, Stafford SL, Link MJ, Garces YI, Foote RL: Single-fraction radiosurgery for presumed intracranial meningiomas: efficacy and complications from a 22-year experience. Int J Radiat Oncol Biol Phys 83:1414-1418, 2012

114. Pollock BE, Stafford SL, Link MJ, Garces YI, Foote RL: Stereotactic radiosurgery of World Health Organization grade II and III intracranial meningiomas: treatment results on the basis of a 22-year experience. Cancer 118:10481054, 2012

115. Pollock BE, Stafford SL, Utter A, Giannini C, Schreiner SA: Stereotactic radiosurgery provides equivalent tumor control to Simpson Grade 1 resection for patients with small- to medium-size meningiomas. Int J Radiat Oncol Biol Phys 55:1000-1005, 2003

116. Pourel N, Auque J, Bracard S, Hoffstetter S, Luporsi E, Vignaud JM, et al: Efficacy of external fractionated radiation therapy in the treatment of meningiomas: a 20-year experience. Radiother Oncol 61:65-70, 2001

117. Reardon DA, Galanis E, DeGroot JF, Cloughesy TF, Wefel JS, Lamborn KR, et al: Clinical trial end points for high-grade glioma: the evolving landscape. Neuro Oncol 13:353-361, 2011

118. Riemenschneider MJ, Perry A, Reifenberger G: Histological classification and molecular genetics of meningiomas. Lancet Neurol 5:1045-1054, 2006

119. Roche PH, Pellet W, Fuentes S, Thomassin JM, Régis J: Gamma knife radiosurgical management of petroclival meningiomas results and indications. Acta Neurochir (Wien) 145: 883-888, 2003

120. Roche PH, Régis J, Dufour H, Fournier HD, Delsanti C, Pellet W, et al: Gamma knife radiosurgery in the management of cavernous sinus meningiomas. J Neurosurg 93 (Suppl 3):68-73, 2000

121. Ron E, Modan B, Boice JD Jr, Alfandary E, Stovall M, Chetrit A, et al: Tumors of the brain and nervous system after radiotherapy in childhood. N Engl J Med 319:10331039, 1988

122. Rosenberg LA, Prayson RA, Lee J, Reddy C, Chao ST, Barnett GH, et al: Long-term experience with World Health Organization grade III (malignant) meningiomas at a single institution. Int J Radiat Oncol Biol Phys 74:427-432, 2009

123. Santacroce A, Walier M, Régis J, Liščák R, Motti E, Lindquist C, et al: Long-term tumor control of benign intracranial meningiomas after radiosurgery in a series of 4565 patients. Neurosurgery 70:32-39, 2012

124. Selch MT, Ahn E, Laskari A, Lee SP, Agazaryan N, Solberg TD, et al: Stereotactic radiotherapy for treatment of cavernous sinus meningiomas. Int J Radiat Oncol Biol Phys 59:101-111, 2004

125. Shin M, Kurita H, Sasaki T, Kawamoto S, Tago M, Kawahara N, et al: Analysis of treatment outcome after stereotactic radiosurgery for cavernous sinus meningiomas. J Neurosurg 95:435-439, 2001

126. Shrieve DC, Hazard L, Boucher K, Jensen RL: Dose fractionation in stereotactic radiotherapy for parasellar meningiomas: radiobiological considerations of efficacy and optic nerve tolerance. J Neurosurg 101 (Suppl 3):390-395, 2004

127. Simon M, Boström J, Koch P, Schramm J: Interinstitutional variance of postoperative radiotherapy and follow up for meningiomas in Germany: impact of changes of the WHO classification. J Neurol Neurosurg Psychiatry 77:767773,2006

128. Simpson D: The recurrence of intracranial meningiomas after surgical treatment. J Neurol Neurosurg Psychiatry 20:22-39, 1957

129. Skeie BS, Enger PO, Skeie GO, Thorsen F, Pedersen PH: Gamma knife surgery of meningiomas involving the cavernous sinus: long-term follow-up of 100 patients. Neurosurgery 66:661-669, 2010

130. Soyuer S, Chang EL, Selek U, Shi W, Maor MH, DeMonte F: Radiotherapy after surgery for benign cerebral meningioma. Radiother Oncol 71:85-90, 2004

131. Spiegelmann R, Nissim O, Menhel J, Alezra D, Pfeffer MR: Linear accelerator radiosurgery for meningiomas in and around the cavernous sinus. Neurosurgery 51:1373-1380, 2002 
132. Stafford SL, Perry A, Suman VJ, Meyer FB, Scheithauer BW, Lohse CM, et al: Primarily resected meningiomas: outcome and prognostic factors in 581 Mayo Clinic patients, 1978 through 1988. Mayo Clin Proc 73:936-942, 1998

133. Stafford SL, Pollock BE, Foote RL, Link MJ, Gorman DA, Schomberg PJ, et al: Meningioma radiosurgery: tumor control, outcomes, and complications among 190 consecutive patients. Neurosurgery 49:1029-1038, 2001

134. Starke RM, Williams BJ, Hiles C, Nguyen JH, Elsharkawy MY, Sheehan JP: Gamma knife surgery for skull base meningiomas. Clinical article. J Neurosurg 116:588-597, 2012

135. Stessin AM, Schwartz A, Judanin G, Pannullo SC, Boockvar JA, Schwartz TH, et al: Does adjuvant externalbeam radiotherapy improve outcomes for nonbenign meningiomas? A Surveillance, Epidemiology, and End Results (SEER)-based analysis. Clinical article. J Neurosurg 117:669-675, 2012

136. Strang RD, Al-Mefty O: Comment on stereotactic radiosurgery for meningioma, in Pollock BE (ed): Contemporary Stereotactic Radiosurgery: Technique and Evaluation. Armonk, NY: Futura Publishing, 2002, pp 172-180

137. Strojan P, Popović M, Jereb B: Secondary intracranial meningiomas after high-dose cranial irradiation: report of five cases and review of the literature. Int J Radiat Oncol Biol Phys 48:65-73, 2000

138. Sughrue ME, Kane AJ, Shangari G, Rutkowski MJ, McDermott MW, Berger MS, et al: The relevance of Simpson Grade I and II resection in modern neurosurgical treatment of World Health Organization Grade I meningiomas. Clinical article. J Neurosurg 113:1029-1035, 2010

139. Sughrue ME, Rutkowski MJ, Aranda D, Barani IJ, McDermott MW, Parsa AT: Treatment decision making based on the published natural history and growth rate of small meningiomas. A review and meta-analysis. J Neurosurg 113:1036-1042, 2010

140. Sughrue ME, Sanai N, Shangari G, Parsa AT, Berger MS, McDermott MW: Outcome and survival following primary and repeat surgery for World Health Organization Grade III meningiomas. Clinical article. J Neurosurg 113:202-209, 2010

141. Tanzler E, Morris CG, Kirwan JM, Amdur RJ, Mendenhall WM: Outcomes of WHO Grade I meningiomas receiving definitive or postoperative radiotherapy. Int J Radiat Oncol Biol Phys 79:508-513, 2011

142. Taylor BW Jr, Marcus RB Jr, Friedman WA, Ballinger WE $\mathrm{Jr}$, Million RR: The meningioma controversy: postoperative radiation therapy. Int J Radiat Oncol Biol Phys 15:299_ 304, 1988

143. Turbin RE, Thompson CR, Kennerdell JS, Cockerham KP, Kupersmith MJ: A long-term visual outcome comparison in patients with optic nerve sheath meningioma managed with observation, surgery, radiotherapy, or surgery and radiotherapy. Ophthalmology 109:890-900, 2002

144. Unger KR, Lominska CE, Chanyasulkit J, RandolphJackson P, White RL, Aulisi E, et al: Risk factors for posttreatment edema in patients treated with stereotactic radiosurgery for meningiomas. Neurosurgery 70:639-645, 2012

145. Uy NW, Woo SY, Teh BS, Mai WY, Carpenter LS, Chiu JK, et al: Intensity-modulated radiation therapy (IMRT) for meningioma. Int J Radiat Oncol Biol Phys 53:1265-1270, 2002

146. Vagefi MR, Larson DA, Horton JC: Optic nerve sheath meningioma: visual improvement during radiation treatment. Am J Ophthalmol 142:343-344, 2006

147. van den Bent MJ, Vogelbaum MA, Wen PY, Macdonald DR, Chang SM: End point assessment in gliomas: novel treatments limit usefulness of classical Macdonald's Criteria. J Clin Oncol 27:2905-2908, 2009
148. van den Bent MJ, Wefel JS, Schiff D, Taphoorn MJ, Jaeckle $\mathrm{K}$, Junck L, et al: Response assessment in neuro-oncology (a report of the RANO group): assessment of outcome in trials of diffuse low-grade gliomas. Lancet Oncol 12:583593,2011

149. Vendrely V, Maire JP, Darrouzet V, Bonichon N, San Galli F, Célérier D, et al: [Fractionated radiotherapy of intracranial meningiomas: 15 years' experience at the Bordeaux University Hospital Center.]. Cancer Radiother 3:311317, 1999 (Fr)

150. Vernimmen FJ, Harris JK, Wilson JA, Melvill R, Smit BJ, Slabbert JP: Stereotactic proton beam therapy of skull base meningiomas. Int J Radiat Oncol Biol Phys 49:99-105, 2001

151. Vogelbaum MA, Jost S, Aghi MK, Heimberger AB, Sampson JH, Wen PY, et al: Application of novel response/ progression measures for surgically delivered therapies for gliomas: Response Assessment in Neuro-Oncology (RANO) Working Group. Neurosurgery 70:234-244, 2012

152. Wara WM, Sheline GE, Newman H, Townsend JJ, Boldrey EB: Radiation therapy of meningiomas. Am J Roentgenol Radium Ther Nucl Med 123:453-458, 1975

153. Wen PY, Macdonald DR, Reardon DA, Cloughesy TF, Sorensen AG, Galanis E, et al: Updated response assessment criteria for high-grade gliomas: response assessment in neuro-oncology working group. J Clin Oncol 28:19631972, 2010

154. Williams BJ, Yen CP, Starke RM, Basina B, Nguyen J, Rainey J, et al: Gamma Knife surgery for parasellar meningiomas: long-term results including complications, predictive factors, and progression-free survival. Clinical article. J Neurosurg 114: 1571-1577, 2011

155. Willis J, Smith C, Ironside JW, Erridge S, Whittle IR, Everington D: The accuracy of meningioma grading: a 10-year retrospective audit. Neuropathol Appl Neurobiol 31:141-149, 2005

156. Winkler C, Dornfeld S, Schwarz R, Friedrich S, Baumann $\mathrm{M}$ : [The results of radiotherapy in meningiomas with a high risk of recurrence. A retrospective analysis.] Strahlenther Onkol 174:624-628, 1998 (Ger)

157. Zachenhofer I, Wolfsberger S, Aichholzer M, Bertalanffy A, Roessler K, Kitz K, et al: Gamma-knife radiosurgery for cranial base meningiomas: experience of tumor control, clinical course, and morbidity in a follow-up of more than 8 years. Neurosurgery 58:28-36, 2006

158. Zada G, Pagnini PG, Yu C, Erickson KT, Hirschbein J, Zelman V, et al: Long-term outcomes and patterns of tumor progression after gamma knife radiosurgery for benign meningiomas. Neurosurgery 67:322-329, 2010

\section{Author Contributions}

Conception and design: all authors. Acquisition of data: all authors. Analysis and interpretation of data: all authors. Drafting the article: Vogelbaum, Rogers. Critically revising the article: all authors. Reviewed submitted version of manuscript: all authors. Approved the final version of the manuscript on behalf of all authors: Vogelbaum.

\section{Supplemental Information}

\section{Current Affiliation}

Dr. Rogers: Department of Radiation Oncology, Virginia Commonwealth University, Richmond, VA.

\section{Correspondence}

Michael A. Vogelbaum, Cleveland Clinic, 9500 Euclid Ave., ND40, Cleveland, OH 44195. email: vogelbm@ccf.org. 